\section{SANDIA REPORT}

SAND96-1031 - UC-511

Unlimited Release

Printed April 1996
RECEIVED

MAY 151996

OSTI

\title{
Recommendations for Computer Modeling Codes to Support the UMTRA Groundwater Restoration Project
}

\author{
Mark D. Tucker, Mushtaq A. Khan
}

Prepared by

Sandia National Laboratories

Albuquerque, New Mexico 87185 and Livermore, California 94550

for the United States Department of Energy

under Contract DE-AC04-94AL85000

Approved for public release, distribution is unlimited. 
Issued by Sandia National Laboratories, operated for the United States Department of Energy by Sandia Corporation.

NOTICE: This report was prepared as an account of work sponsored by an agency of the United States Government. Neither the United States Government nor any agency thereof, nor any of their employees, nor any of their contractors, subcontractors, or their employees, makes any warranty, express or implied, or assumes any legal liability or responsibility for the accuracy, completeness, or usefulness of any information, apparatus, product, or process disclosed, or represents that its use would not infringe privately owned rights. Reference herein to any specific commercial product, process, or service by trade name, trademark, manufacturer, or otherwise, does not necessarily constitute or imply its endorsement, recommendation, or favoring by the United States Government, any agency thereof or any of their contractors or subcontractors. The views and opinions expressed herein do not necessarily state or reflect those of the United States Government, any agency thereof or any of their contractors.

Printed in the United States of America. This report has been reproduced directly from the best available copy.

Available to DOE and DOE contractors from

Office of Scientific and Technical Information

PO Box 62

Oak Ridge, TN 37831

Prices available from (615) 576-8401, FTS 626-8401

Available to the public from

National Technical Information Service

US Department of Commerce

5285 Port Royal Rd

Springfield, VA 22161

NTIS price codes

Printed copy: A05

Microfiche copy: A01 


\section{DISCLAMAR}

Portions of this document may be illegible in electronic image products. Images are produced from the best available original document. 
SAND96-1031

Unlimited Release

Distribution

Printed April 1996

Category UC-511

\title{
Recommendations for Computer Modeling Codes to Support the UMTRA Groundwater Restoration Project
}

\author{
Mark D. Tucker \\ Senior Member of Technical Staff \\ Sandia National Laboratories \\ Albuquerque, NM 87185-0734 \\ Mushtaq A. Khan \\ IT Corporation \\ 5301 Central Avenue NE, Suite 700 \\ Albuquerque, NM 87108-1513
}

\begin{abstract}
$\underline{\text { Abstract }}$
The Uranium Mill Tailings Remediation Action (UMTRA) Project is responsible for the assessment and remedial action at the 24 former uranium mill tailings sites located in the United States. The surface restoration phase, which includes containment and stabilization of the abandoned uranium mill tailings piles, has a specific termination date and is nearing completion. Therefore, attention has now turned to the groundwater restoration phase, which began in 1991. Regulated constituents in groundwater whose concentrations or activities exceed maximum contaminant levels (MCLs) or background levels at one or more sites include, but are not limited to, uranium, selenium, arsenic, molybdenum, nitrate, gross alpha, radium-226 and radium-228. The purpose of this report is to recommend computer codes that can be used to assist the UMTRA groundwater restoration effort. The report includes a survey of applicable codes in each of the following areas: 1) groundwater flow and contaminant transport modeling codes, 2) hydrogeochemical modeling codes, 3) pump and treat optimization codes, and 4) decision support tools. Following the survey of the applicable codes, specific codes that can best meet the needs of the UMTRA groundwater restoration program in each of the four areas are recommended.
\end{abstract}


(this page left blank) 


\section{Table of Contents}

1. Introduction

3
A. UMTRA
B. Computer Modeling Codes

2. Groundwater Flow and Contaminant Transport Modeling Codes
A. Introduction
B. Overview
C. Recommended Groundwater Flow/Contaminant Transport Codes

3. Hydrogeochemical Modeling Codes
A. Overview
B. Recommended Hydrogeochemical Modeling Codes

4. Pump and Treat Optimization Modeling Codes
A. Overview
B. Pump and Treat System Optimization Strategies
C. Recommended Pump and Treat Optimization Codes

5. Decision Support Tools
A. Overview
B. Recommended Decision Support Tools

6. Conclusions
A. Summary of Code Survey
B. Code Sources
C. Future Development Work

7. References

8. Acknowledgments 
(this page left blank) 


\section{Section 1 \\ Introduction}

\section{A. UMTRA}

The UMTRA Project was authorized by the Uranium Mill Tailings Radiation Control Act of 1978 (UMTRCA). This act established a program of assessment and remedial action at 24 inactive uranium mill sites in the United States to dispose of, stabilize, and control residual radioactive material. Residual radioactive material is defined as "radioactive waste in the form of tailings resulting from the processing of ores for the extraction of uranium and other valuable constituents, and other radioactive waste at a processing site which relates to such processing" (DOE/UMTRA, 1993). The purpose of the UMTRA project is to ensure that radiological and nonradiological hazards at the sites do not exceed the standards established by the U.S. Environmental Protection Agency (EPA) and the U.S. Department of Energy (DOE) for the protection of public health, safety, and the environment (DOE/UMTRA, 1993).

Until recently, most work in the UMTRA project has centered on surface activities to contain and stabilize uranium mill tailings piles. Because the surface restoration phase has a specific termination date and is nearing completion, attention has now turned to groundwater restoration. Work on the groundwater restoration phase has been on-going since 1991. Tailings-related contamination of groundwater is present beneath and down-gradient from many of the processing sites. Regulated constituents in groundwater whose concentrations or activities exceed maximum contaminant levels (MCLs) or background levels at one or more sites include, but are not limited to, uranium, selenium, arsenic, molybdenum, nitrate, gross alpha, radium226 and radium-228. To ensure that technically and financially sound groundwater restoration technologies are selected for implementation at UMTRA sites, the observational approach has been proposed since there appears to be no imminent threat to public health, safety or the environment (DOE/UMTRA 1993). The observational method establishes a remedial design based on most probable site conditions, identifies reasonable deviations from those conditions, identifies parameters to observe so that those deviations may be detected during restoration work, and provides contingency plans for each potential deviation. The observational approach uses a series of iterative steps which include characterization of a site, definition and refinement of a conceptual model of the site, and identification of 
uncertainties in the conceptual model. Successful implementation of the observational approach requires tools that optimize the use of available information. These tools include expert judgment, numerical models and statistical techniques (DOE/UMTRA, 1993).

The purpose of this report is to recommend computer codes that can be used at the present time or in the near future to support the observational approach to groundwater restoration at UMTRA sites. It is necessary to point out that there are a large number of computer modeling codes available and part of this effort is to narrow down the available codes to a manageable number. Not every available code is reviewed in this report. It is also necessary to understand that no single code is appropriate over a wide range of conditions. UMTRA personnel may use the information contained in this report to find other available codes to support the groundwater restoration effort as needs change or become better defined.

The information contained in this report was obtained solely from a review of available literature. In many cases, the source of this literature was the code developer or software distributor. No codes were actually tested for quality, reliability or functionality.

Recommendations are made for the following categories of computer codes: 1) groundwater flow and contaminant transport modeling codes, 2) hydrogeochemical modeling codes, 3) pump and treat optimization codes, and 4) decision support tools. For each category, a survey of the various codes that are currently available are first presented. Then, specific codes are recommended for use by the UMTRA groundwater restoration project. These recommendations are based on the following criteria: 1) the availability of the code, 2) the cost of the code, 3) the platform required to run the code, and 4) the ability of the code to meet UMTRA needs as understood at the current time. Preference is given to codes that are widely used, inexpensive, and run on low-cost platforms especially those already used by the UMTRA project. Recommendations for future code development are also made in categories where the currently available codes do not meet the needs of the UMTRA groundwater restoration project. However, only codes that can be completed in a short time frame (i.e., less than 2 years) are recommended for future development effort.

To facilitate the understanding of the recommendations contained in this report, some background information is presented below. This background information plays a key role in the selection and recommendation process for code selection. 


\section{B. Computer Modeling Codes}

A major part of this report provides recommendations concerning computer codes which can be used to model groundwater flow and transport, to identify hydrogeochemical characteristics of an aquifer, to optimally design pump and treat systems, and to provide decision support to the UMTRA Project. While recommendations are being made, it is necessary to provide a brief overview of the process involved in making such recommendations and the further steps necessary to take the process to implementation.

Modeling usually involves the following steps:

- Establish the purpose of the model

- Development of a conceptual model

- Selection of model software

- Model design and development of the model database

- Model calibration

- Sensitivity analysis

- Model prediction

For the benefit of those who have not had any training or experience in this area a brief description of each step is provided. These descriptions are found in Anderson and Woessner (1992).

1. Establish the purpose of the model which will determine the governing equation to be solved and the code to be selected.

2. Develop a conceptual model of the system. Identify hydrostratigraphic units and system boundaries. Assemble field data including information on water balances, aquifer parameters, hydrologic stresses, and groundwater concentrations.

3. Select the governing equations and a computer code. The code is a computer program that contains an algorithm to solve the mathematical model. Both the governing equations and the computer code should be verified. Verification of the governing equations demonstrates that they accurately represents physical processes that occur at the site. Verification of the computer code demonstrates that the code accurately solves the equations that constitute the mathematical model. 
4. Model design is conducted to put the conceptual model in a form suitable for modeling the actual site. This step includes design of the grid, selection of time steps, setting boundary and initial conditions, and preliminary selection of values for aquifer parameters and hydrologic stresses. Storage of this information in a designated format will constitute development of the model database.

5. The model is calibrated to establish that the model can reproduce field-measured heads, flows, and concentrations. During calibration, a set of values for aquifer parameters and stresses is found that approximates field-measured heads, flows, and concentrations. Calibration is accomplished by trial-and-error adjustment of parameters or by using an automated parameter estimation code.

6. The calibrated model is influenced by uncertainty due to the inability to define exact spatial and temporal distributions of aquifer and transport parameters. A sensitivity analysis is performed to determine the effects of uncertainty in parameter values on model results.

7. Model prediction quantifies the response of the system to future events. The model is run with calibrated values for parameters and stresses, except for those stresses that are expected to change in the future. 


\section{Section 2 \\ Groundwater Flow and Contaminant Transport Modeling Codes}

\section{A. Introduction}

Use of the observational approach to remediate contaminated groundwater at UMTRA sites requires further understanding of the properties of the subsurface media where contamination has occurred. This process may involve additional field testing, experimental work in the laboratory, and computer modeling. Computer codes that simulate flow and contaminant transport in aquifers and other soils will be important tools for implementing the observational approach. These codes can be used to estimate the rate and direction of groundwater flow under a variety of hydrogeologic conditions. Numerical transport modeling may also be used to demonstrate compliance with groundwater cleanup standards. Seepage and leaching from disposal cells can also be evaluated to determine whether groundwater cleanup standards can be met by natural attenuation or flushing. Most codes can calculate contaminant transport rates by accounting for advection, dispersion and chemical reactions. Computer codes can be used to design optimal monitoring and extraction well networks, determine capture zones around pumping wells, predict groundwater flow paths to aid in the understanding of contaminant transport, and predict the nature and extent of contamination. There are four general areas where flow and transport codes could be used to support groundwater restoration at UMTRA sites (Baker and Herson, 1994):

- Flow in the Saturated Zone

- Flow in the Unsaturated Zone

- Flow in Fractures

- Transport Models

Prior to the discussion on the various applicable models, a brief description of each of these four areas is presented below.

\section{A.1 Flow in the Saturated Zone}

This type of modeling is well established for fully saturated porous media. With the exception of unconfined groundwater flow, the equations are linear, 
and simple mathematical models generally give good results. One-dimensional (1D) or two-dimensional (2D) models are often sufficient, although threedimensional (3D) models are becoming more common. Assumptions of steadystate flow, spatial homogeneity, and applications of Darcy's law (invalid for high velocity flows near well screens) are common. The models simulate spatial variations in hydraulic potential, a parameter that is frequently referred to as hydraulic head.

A significant amount of data input is often required, even for simple flow models that take into account spatial heterogeneity. Parameter estimation is a critical step both during the model design and model calibration phases. It is important to decide whether a one-, two- or three-dimensional model is required during the conceptual model stage. The physical boundary conditions must be known or estimated and the model user must make sure that steadystate flow conditions apply to a site before the assumption of equilibrium flow is invoked in a model.

\section{A.2 Flow in the Unsaturated Zone}

Modeling of the flow in the unsaturated zone has become relatively common. Water flow in the unsaturated zone is often transient because of the transient nature of recharge and fluid transport from the ground surface to the water table. However, steady-state conditions may be assumed for sites where the unsaturated zone exhibits a state of dynamic equilibrium over periods of several years. Infiltration at the surface is governed by soil properties and recent soil moisture history. Water flows through the unsaturated zone seeking a quasi-equilibrium distribution of hydraulic head. When the transition to equilibrium is complete, the zone is hydraulically static and the only flow sources and sinks are evapotranspiration and condensation. The pores in the unsaturated zone are filled with water, gases and possibly non-aqueous phase liquids (NAPLS). The degree of saturation depends on soil properties and surface sources/sinks. Hydraulic conductivity is a nonlinear variable in unsaturated soils and is proportional to the degree of saturation for the phase in question. Flow of a particular phase is proportional to the potential gradient of head in that phase. 


\section{A.3 Flow in Fractures}

Modeling of flow in fractures is still considered to be in the research stage. Fractures (joints, faults, shear zones) result from a wide range of geological processes. They are quite common and vary a great deal in size, shape distribution, and the ability to transmit fluids. The porosity created by fracturing is superimposed on the original matrix porosity and may exceed it by several orders of magnitude.

Flow in open fractures may approximate conduit flow, and the applicability of Darcy's law may come into question. Fractures are often modeled as a simple channel between parallel plates. This modeling technique is in contrast to the fact that fracture surfaces are found to be rough rather than smooth. In addition, fractures may be either open or closed as a function of the chemical or physical transport process and of pressure or depth. The current fracture modeling efforts include:

1. Single parallel-plate models which predict flow through a network of discrete fractures (of specific location, orientation, and property).

2. Dual-porosity models which calculate flow in fractures, flow in the porous matrix separately, and apply a transfer function to the surface area between the two phases.

3. Models which approximate the fractured rock using an equivalent porous medium with a modified hydraulic conductivity.

\section{A.4 Transport Models}

Modeling of transport in the saturated and unsaturated zones is relatively common, while transport modeling in fractured rocks is still in the research stage. Since transport models seek to predict the concentration of substances as a result of fluid movement in addition to chemical fate, a good fluid flow model is essential for providing a transport model. Advection often dominates the transport of contaminants to such a degree that the influence of other processes becomes negligible. The equations used to model combined advective-dispersive contaminant transport are simplified approximations of actual transport. Often, linear equilibrium relationships between various flow phases are assumed, which is relatively straightforward to model. Nonlinear reactions are more difficult. It is also difficult to get numerous and varied field data needed to calibrate these models. The compositional variability of the 
porous medium is a much greater issue in transport modeling than medium heterogeneity is for groundwater flow modeling. This is because changes in hydraulic conductivity over very small distances tend to create preferred transport paths that strongly affect concentrations but do not show a proportional effect on heads.

\section{B. Overview}

A very large number of codes exist to model groundwater flow and transport. This report makes no attempt to describe every available code. Instead, only codes applicable to UMTRA sites are reviewed. Several codes which can potentially meet the needs of the UMTRA groundwater restoration effort for groundwater flow and contaminant transport studies are described below.

\section{FLONET/FLOTRANS}

\section{Version 2.2}

Developer: Waterloo Hydrogeologic Software, Waterloo, Ontario, Canada FLONET is a widely-used 2D cross-sectional, steady-state, finite element, groundwater flow model. It computes potentials, streamlines, and groundwater velocities in a vertical section through confined or unconfined aquifers. FLONET is based on the dual formulation of potentials and stream functions. Heterogeneous and anisotropic porous media under complex boundary conditions can be simulated. Spatially variable recharge rates can be considered in this code. For unconfined aquifers, the model seeks the water table surface iteratively. The grid nodes are relocated automatically to conform with the final position of the water table. FLOTRANS, an extension of FLONET, is a transient contaminant transport model. Biodegradation and chemical transformation processes can be represented by a firstorder decay function. Different decay rates can be applied to the source and to the contaminant within the aquifer. Adsorption can also be represented through linear retardation. Spatially variable initial concentrations and internal contaminant sources can be considered. FLONET and FLOTRANS are self-contained packages where all data input is done through an interactive graphical user interface (GUI) (Scientific Software Group, 1995).

System Requirements

- Intel 386/486 based computer

- mouse (recommended)

- 4 Mb RAM

- math coprocessor 


\section{FTWORK}

Version 2.8

Developer: C.R. Faust et al., GeoTrans, Inc.

FTWORK is a block-centered, finite-difference model for simulating one-, two- or three-dimensional steady-state or transient flow and transient single-species solute transport in saturated media under confined and unconfined conditions. The model supports both areal and cross-sectional 2D flow simulations. The flow equation is posed in terms of hydraulic head and the transport equation in terms of concentration. Both aquifer heterogeneities and anisotropy can be handled. Transport processes include advection, hydrodynamic dispersion, first order decay (chemical, biological or radioactive) and linear and nonlinear equilibrium adsorption. Cross-product terms for dispersion can be included for solute transport. A parameter estimation option (semiautomatic history matching) of the steady-state flow equation, using a Gauss-Newton non-linear least-squares optimization technique with a Marquardt correction is also included in the model. The model supports variable grid block lengths in all three dimensions and deformed coordinate approximation for variable thickness layers. Boundary conditions include prescribed head, prescribed concentration, prescribed flux of water or solute mass, and head-dependent flux. It also handles single- and multi-aquifer wells and chemical sources and sinks. A proprietary textual preprocessor, PRE-FTW, is available from the International Groundwater Modeling Center, Boulder, CO. PRE-FTW provides menu-driven, mouse-operated, interactive data entry and editing (IGWMC, 1995).

System Requirements

- Intel 386/486 based computer

- DOS 5.0 or higher

- $11 \mathrm{Mb}$ RAM

- Windows 3.1 for PRE-FTW

- math coprocessor

- CGA graphics

\section{GMS}

Version 1.1

Developer: U.S. Department of Defense

GMS (Groundwater Modeling System), a comprehensive graphical modeling environment developed by the U.S. Department of Defense, is designed for the simulation of groundwater flow and transport. GMS integrates and simplifies the process of groundwater flow and transport by packaging the tools under an easy-touse GUI. GMS is designed to work with the MODFLOW/MT3D codes (described in 
this report) and the FEMWATER-based groundwater flow and transport models. FEMWATER is a fully $3 \mathrm{D}$ finite element flow and transport model that provides density-driven, coupled flow and contaminant transport under both saturated and unsaturated conditions. Features of GMS include 2D and 3D mesh generation, graphically-based model input for flow and transport parameters, interpolation and geostatistics, DXF input and output, and 3D visualization. To assist site characterization and database development, GMS provides an extensive set of tools for modeling the stratigraphy of a site. Borehole data in the form of ASCII input files can be used to graphically build solid models of subsurface features. Fence diagrams and cross sections can be generated to illustrate these features. GMS automates the process of mesh generation with a comprehensive set of tools to generate $2 \mathrm{D}$ and $3 \mathrm{D}$ finite element and finite difference grids. These tools can utilize site maps directly from AutoCAD to define boundaries and interior features. GMS has integrated a variety of $2 \mathrm{D}$ and $3 \mathrm{D}$ geostatistical and interpolation methods. Kriging and other methods can be used to characterize 2D and 3D contaminant plumes and for defining initial conditions and material properties for groundwater models. GMS also has coupled flow and transport models with state-of-the-art scientific visualization including both 2D and 3D graphics (Scientific Software Group, 1995).

System Requirements

- Intel 386/486/Pentium based computer

- $\quad$ Microsoft Windows 3.1

- $16 \mathrm{Mb}$ RAM (32 Mb RAM recommended)

- math coprocessor

$\underline{\mathrm{OR}}$

- UNIX X-Windows with workstation (i.e., IBM RS6000, Sun Sparcstation, HP 9000 Series 700/800, Silicon Graphics, or DEC Alpha)

\section{HYDROGEOCHEM}

Version 2.0

Developers: G.T. Yeh and V.S. Tripathi (Oak Ridge National Laboratories)

HYDROGEOCHEM is a coupled model for hydrological transport and geochemical equilibrium reactions. The transport model can be applied to heterogeneous, anisotropic, saturated/unsaturated subsurface media under either transient or steadystate conditions. The geochemical equilibrium processes included in the model are aqueous complexation, adsorption/desorption, ion exchange, precipitation/dissolution, oxidation/reduction, and acid/base reactions. Spatially and temporally dependent element and point sources/sinks are included in the model. Boundary conditions 
include prescribed concentrations on Dirichlet boundaries, prescribed fluxes on inflow or no-flow boundaries, and natural advective fluxes on outflow boundaries. Transport is described by a set of partial differential equations (PDEs) and the chemical reactions are described by a set of nonlinear algebraic equations (AEs). The system is considered as coupled linear PDEs and nonlinear AEs and a solution is arrived at by solving iteratively between these two sets of equations. This permits fast, nonnegative, convergent solutions which includes a full complement of chemical processes (Yeh and Tripathi, 1990). The model, which is based on finite element techniques, uses quadrilateral elements, triangular elements, or a mixture of these two types. Approximation options include consistent matrix or mass lumping, nodal quadrature, or Gaussian Quadrature for surface and element integrations. This code can model hydrologic transport and contaminant reactions in heterogeneous and anisotropic media under both saturated and unsaturated conditions (Scientific Software Group, 1995).

System Requirements

- Intel 386/486/Pentium based computer

- $\quad 16 \mathrm{Mb} \mathrm{RAM}$

- Fortran compiler

$\underline{\mathrm{OR}}$

- Any workstation (i.e., IBM RS6000, DEC Alpha, Silicon Graphics, Sun Sparcstation, and HP 9000 Series)

\section{INTERSAT/INTERTRANS}

Version 5.0

Developers: Environmental Science \& Engineering Inc./Hydrosoft, Inc., Sarasota, FL

INTERSAT and INTERTRANS are 3D groundwater flow and solute transport codes. INTERSAT is a point-centered, finite difference, steady state or transient flow model patterned after PLASM developed by Prickett and Lonnquist (1971). The model grid can be uniform or variable. Features simulated include: 1) homogeneous, heterogeneous, isotropic, and anisotropic aquifer system layers and stratified aquifers, 2) constant-head, no flow (barrier), and variable flux (recharge and/or discharge wells at adjacent grid nodes) boundaries, 3) uniform or variable initial head distribution, 4) streambed induced infiltration (streams or lakes can penetrate one or more aquifer layers) with uniform or variable stream stages, uniform or variable streambed dimensions, with or without maximum leakage rates, and constant streambed hydraulic conductivity, 5) stream drainage and drains, 6) uniform or variable areal 
recharge, 7) fully penetrating production and/or recharge wells with constant or variable discharge or recharge rates, 8) heads in production wells, and 9) evapotranspiration. In addition, INTERSAT simulates mine, surface water impoundment, excavation, or borrow pit dewatering with changing (nonstationary) surface water stages and storage, 3D symmetric flow, and partially penetrating wells. INTERSAT does not simulate fractured aquifers, aquitard storativity under leaky artesian conditions, delayed gravity drainage under water-table conditions, groundwater/surface water logging, unsaturated conditions under streambeds, wellbore storage, collector wells, and multi-aquifer wells. INTERTRANS is a random-walk model patterned after RANDOM WALK developed by Prickett et al. (1981). The model simulates 3D conservative or nonconservative solute transport in steady-state or transient groundwater flow through one or more aquifer system layers. INTERSAT head, grid and aquifer system database files are imported by INTERTRANS which employs particle tracking to describe advective and dispersive contaminant migration. Advection is simulated as particle movement along streamlines of the flow velocity field and dispersion is simulated as a random particle movement using statistical properties related to the size of the dispersion coefficients (Walton, 1992).

\section{System Requirements}

- Intel 386/486 based computer

- $4 \mathrm{Mb}$ RAM (16 Mb recommended)

- math coprocessor

- EGA or VGA graphics card

- Microsoft Windows 3.x

\section{LEHGC}

Version 1.1

Developers: G.T. Yeh (Pennsylvania State University)

LEHGC is a finite element model designed to simulate contaminant transport through saturated/unsaturated media. LEHGC solves a set of 2D, partial differential equations describing transport with a hybrid Lagrangian-Eulerian finite element method. The system of transport equations and a separate subsystem of geochemical equations are solved in an iterative fashion. The transport equations, along with the initial and boundary conditions and the geochemical equilibrium equations, govern the migration and chemical reactions of multicomponent species. The transport equations include terms for advection, dispersion, diffusion, sources/sinks, and mass production/reduction due to radioactive decay and chemical reactions. The chemical 
reactions considered are aqueous complexation, adsorption/desorption, ion exchange, precipitation/dissolution, oxidation/reduction, and acid/base reactions. This code is currently under development. Future versions will allow execution of the code on massively parallel computers and replacement of the equilibrium chemistry model with a kinetic model (Yeh, 1993).

\section{System Requirements}

- IBM PC compatible system

\section{MODFLOW}

\section{Version 1.31}

Developers: M.G. McDonald and A.W. Harbaugh (U.S.G.S)

MODFLOW is a finite difference model designed to simulate quasi- or fully-3D steady-state or transient flow in anisotropic, heterogeneous, layered aquifer systems (IGWMC, 1995). It can also be applied to 2D areal or cross-sectional flow problems. MODFLOW EXT is an extended memory version of the original MODFLOW model. The model is based on a block-centered finite difference approach and can use variable grid spacing in three dimensions. Layers can be simulated as confined, semiconfined, unconfined, or convertible between two conditions (McDonald and Harbaugh, 1984). The model can also represent layers that pinch out and can allow for analysis of external influences such as constant or time-varying wells, areal recharge, drains, evapotranspiration, and streams. First, second, or third type boundary conditions (both constant and time-varying) can be implemented in this model. PREMOD, an interactive preprocessor developed by GeoTrans, Inc., is also available for this model. POSTMOD, a post-processor developed by the International Ground Water Modeling Center, reformats MODFLOW output into a format compatible with commercial contouring packages. Recent modules added to the MODFLOW package allow the simulation of aquifer compaction due to groundwater withdrawal (Leake and Prudic, 1991), coupled surface-water/groundwater dynamically connected systems (Swain and Wexler, 1993), low-permeable barriers (Hsieh and Freckleton, 1993), and analytical solutions for transient leakage from confining units (Leake et al., 1994).

\section{System Requirements}

- Intel 80386/80486 based computer

- 4 Mb RAM

- EGA or VGA graphics
- DOS 3.0 or higher

- math coprocessor

- about 1.5 Mb free disk space 


\section{MODPATH}

Version 3

Developer: D.W. Pollock (U.S.G.S)

MODPATH (along with MODPATH-PLOT) are particle tracking post-processing programs developed to compute 3D pathlines based on output from steady-state or transient simulations from MODFLOW. MODPATH actually computes the pathlines while MODPATH-PLOT presents the results graphically. MODPATH uses a semianalytical particle tracking scheme which is based on the assumption that each directional velocity component varies linearly within a grid cell in its own coordinate direction. This allows an analytical expression to be obtained describing the flow path within a grid cell. The time of travel between the initial position of a particle and any point along the flow path can be calculated. Data are input to MODPATH through a combination of files and interactive dialogue. MODPATH-PLOT source code must be linked to either the DISSPLA graphics library or the Graphical Kernel System (GKS) to generate graphical output (IGWMC, 1995).

System Requirements

- Intel 80386/80486 based computer

- 4 Mb RAM

- EGA or VGA graphics

- DISSPLA or GKS graphics library optional
- DOS 3.0 or higher

- math coprocessor

- at least $5 \mathrm{Mb}$ free disk space

\section{MT3D}

\section{Version 1.85}

Developer: C. Zheng (S.S. Papadopulos \& Assoc.)

MT3D is a 3D transport model for simulation of advection, dispersion, and chemical reactions of dissolved constituents in groundwater (IGWMC, 1995). MT3D is intended for use with block-centered finite difference flow models such as MODFLOW and is based on the assumption that changes in concentration will not affect the flow field so that the user can independently construct and calibrate a flow model. MT3D retrieves the hydraulic heads and the various flow and sink/source terms saved by the flow model while automatically incorporating specified hydrologic boundary conditions. MT3D can be used to simulate changes in concentration of single-species miscible contaminants in groundwater considering advection, dispersion and chemical reactions. Chemical reactions in the model include equilibriumcontrolled linear and non-linear sorption, first-order irreversible decay, and 
biodegradation (Zheng, 1990). MT3D will also accommodate confined, unconfined, or variably confined/unconfined aquifer layers, inclined model layers and variable cell thickness within the same layer, specified concentration or mass flux boundaries, and solute transport effects of external sources and sinks such as wells, drains, rivers, areal recharge, and evapotranspiration. MT3D creates output files which can be read by commercial contouring packages.

\section{System Requirements}

- Intel 80386/80486 based computer

- DOS 3.0 or higher

- $2 \mathrm{Mb}$ RAM

- math coprocessor

- at least $1 \mathrm{Mb}$ free disk space

\section{PATH3D}

Version 3.0

Developer: C. Zheng (S.S. Papadopulos \& Associates, Inc.)

PATH3D is a general particle tracking program for calculating groundwater paths and travel times in steady-state or transient 2D or 3D flow fields. PATH3D can be used to simulate the movement of groundwater flows and the advection of contaminant solutes in groundwater. The program can be used for delineating contaminant capture zones or well-head protection zones in order to evaluate the effectiveness of groundwater pollution control under complex hydrological conditions. PATH3D includes two segments: 1) a velocity interpolator which converts the hydraulic heads calculated at discretized nodal points into a velocity field in which the velocity in a given time step is determined as a function of position, and 2) a numerical solver for tracking the movement of fluid particles in groundwater flow systems. In the first segment, PATH3D uses a block-centered finite difference approach. In the second segment, the code uses a fourth-order Runge-Kutta solution capable of automatic stepsize adjustment to achieve pre-determined accuracy with minimum computational effort. PATH3D uses the head solution of the U.S. Geological Survey modular 3D finite-difference flow model MODFLOW. This allows flexibility in handling a wide range of field problems including the presence of wells, drains, rivers, recharge, and evapotranspiration, and permits a large variety of boundary conditions. The input file and resulting head file from MODFLOW are used directly by PATH3D. However, PATH3D can also be used with other block-centered finite-difference flow models. PATH3D generates several output files including: 1) the $x, y, z$ coordinates and the components of the seepage velocity at different travel times along the path of each 
individual particle, 2) the $\mathrm{x}, \mathrm{y}, \mathrm{z}$ coordinates of all particles at selected times, and 3) the initial and final positions of those particles captured by various sinks, or sources in the case of reverse tracking. These output files can be imported into most commercial graphic packages for plotting pathlines of individual particles, the positions of displacement fronts of capture zones at desirable times, and the distribution of captured particles (Zheng, 1988).

System Requirements

- Intel 386/486 based computer (for 32 bit version)

\section{PHREEQM}

Version 2.01

Developers: P.R. Nienhuis, C.A.J. Appelo, A. Willemsen

PHREEQM is a 1-D mixing cell model based on the USGS mass transfer code PHREEQE (reviewed in Section 3 of this report). PHREEQM can handle both dispersive mixing, which is caused by concentration, temperature, and electrical gradients, and mass transfer mixing, which is caused by mass transfer between heterogeneous phases in systems which have not achieved chemical equilibrium. PHREEQM simulates advective flow by transporting single-cell volumes in batches of "shifts". thereby decoupling the advective and dispersive processes. Dispersion is simulated by calculating a mixing factor and mixing each cell with adjoining cells. The mixing factor essentially corresponds to a finite-difference formulation, centeredin-space, and forward-in-time (Appelo and Willemsen, 1987).

System Requirements

- Intel 80386/80486 based computer

- $400 \mathrm{~Kb}$ RAM

- DOS 3.0 or higher

- math coprocessor

\section{PLASM}

Version 2.11

Developers: T.A. Prickett and C.G. Lonnquist (Illinois State Water Survey)

PLASM consists of three finite difference simulation programs and a preprocessor (IGWMC, 1995). The model is based on the Prickett-Lonnquist Aquifer Simulation Program first published in 1971. It was one of the first readily available, welldocumented groundwater flow models (Anderson and Woessner, 1992). The programs simulate $2 \mathrm{D}$ nonsteady flow of groundwater in heterogeneous, anisotropic aquifers under unconfined, non-leaky confined and leaky confined conditions in both 
areal and profile orientations. It is a node-centered model but can accommodate block-centered flux boundary conditions. PLASM requires the user to assign a storage parameter to the area around a node and to specify transmissivities for the area between nodes. Options for time-varying pumpage from wells, induced infiltration from streams or shallow aquifers, and evapotranspiration are included. The finite difference equations are solved using the alternating direction implicit method. The three simulation programs include: 1) PLASM85, simulation of transient flow in a fully confined aquifer, 2) CONPLASM, simulation of transient flow in a fully confined or leaky confined aquifer, and 3) UNCPLASM, simulation of transient flow in an unconfined aquifer.

\section{System Requirements}

- Intel 80i86 based computer

- $640 \mathrm{~Kb}$ RAM

- DOS 2.1 or higher

- about $1.5 \mathrm{Mb}$ free disk space

\section{RAND3D}

Version 1.0

Developers: D. Koch (Engineering Tech. Assoc.) and T.A. Prickett (Illinois State Water Survey)

RAND3D is a 3D random walk model for solving groundwater solute transport problems. It is a 3D version of RANDOM WALK. The model includes the following features: 1) calculation of horizontal advective transport using one of three different velocity interpolation schemes, 2) calculation of vertical advective transport based on linear interpolation between the input vertical velocity vectors at the top and bottom of each layer, 3) calculation of dispersion using constant dispersivities, 4) calculation of zero-order, first-order, or variable-order decay, or volatilization from the water table, 5) calculation of linear adsorption (retardation), 6) ability to represent complex areal sources, 7) calculation of solute concentrations exiting the model at sinks (wells or gaining streams), 8) cross section or plan view contour mapping in user selected areas of the model, 9) output of gridded solute concentrations by layer for plotting, 10) interactive screen graphics including plume movements, geographic features, and screen slides, 11) saving and restart of model parameters at any time, 12) transient flow simulation capability by running multiple time steps, 13) particle splitting to improve resolution by adding increased particles based on a multiple of the original number of particles selected, 14) particle transfer to simulate solute transport problems at different scales and pass particles from one sized RAND3D model to 
another sized RAND3D model as an input file, and 15) dynamic memory management including automatic redimensioning of arrays to minimize memory use by the model. A preprocessor, PREMOD3D, is available to take MODFLOW input files from a calibrated MODFLOW run and create velocity vector files which may be used to run RAND3D.

\section{System Requirements}

- Intel 80i86 based computer

- DOS 3.0 or higher

- $640 \mathrm{~Kb}$ RAM

- CGA Graphics

- about 3.5 Mb free disk space

\section{RANDOM WALK}

Version 1.0

Developers: T.A. Prickett et al. (Illinois State Water Survey)

RANDOM WALK is a groundwater flow model for the simulation of 2D flow and solute transport (IGWMC, 1995). Solutions for groundwater flow include analytical solutions and a finite difference formulation. RANDOM WALK can simulate 2D nonsteady/steady flow problems in heterogeneous aquifers under confined, nonleaky confined, and leaky confined conditions. The program can handle time-varying pumpage or injection by wells, natural or artificial recharge, flow relationships between surface water and groundwater, evapotranspiration, conversion of storage coefficients from confined to unconfined conditions, and flow from springs. The program allows a variety of water quality conditions, injection of solute by wells, leachate entering the aquifer, salt water intrusion, and leakage of water from overlying or underlying aquifers. The program runs in batch mode and supports variable (rectangular) grid cells, various time stepping options, and extensive output.

\section{System Requirements}

- Intel 80i86 based computer

- $640 \mathrm{~Kb}$ RAM

- DOS 2.0 or higher

- about 1.0 Mb free disk space

- math coprocessor

\section{SUTRA}

\section{Version V06902D}

Developers: C.I. Voss (U.S. Geological Survey)

SUTRA is a saturated-unsaturated, finite element, groundwater flow and transport model. SUTRA combines finite elements and integrated finite differences to simulate 
2D problems under saturated and partially saturated conditions. The model can be used for $2 \mathrm{D}$ areal and cross-sectional modeling of saturated flow systems, and for cross-sectional, ID vertical modeling of unsaturated flow. Specific uses of the model include: 1) assessment of well performance and pumping test data, 2) densitydependent flow or constant-density flow analysis in both saturated and unsaturated zones, 3) analyses of chemical species transport, including solute sorption, production and decay, 4) prediction of hazardous waste migration from land disposal sites, 5) analysis of aquifer restoration, waste confinement, hydraulic barriers, liners and water-quality protection systems, and 6) modeling of variable-density leachate movement. SUTRA-PLOT, which is included with SUTRA, is a menu-driven graphics program that is capable of generating contour plots of temperature, concentration, pressure, and saturation. Mesh plots of the finite element model may also be generated (Scientific Software Group, 1995).

\section{System Requirements}

- Intel 386/486 based computer

- $4 \mathrm{Mb}$ RAM

- $\quad 2.5 \mathrm{Mb}$ free disk space
- EGA/VGA Graphics card

- math coprocessor

- Microsoft Windows 3.x

\section{SWIFT/486}

\section{Version 2.54}

Developers: GeoTrans, Inc., Sterling VA

SWIFT/486 is a transient, fully-3D model which simulates the flow and transport of fluid, heat (energy), brine, and radionuclide chains in porous and fractured geologic media. Both Cartesian and cylindrical coordinates may be used in the model. The primary equations for fluid, heat and brine flow and transport are coupled by fluid density, fluid viscosity, and porosity. For simulation of flow in fractured media, the model supports both dual-porosity and discrete fracture network conceptualizations. Migration within the rock matrix is characterized as a 1D process. SWIFT/486 can model heterogeneous and anisotropic aquifers under confined and unconfined conditions and includes linear and nonlinear (Freundlich) isothermal equilibrium adsorption, hydrodynamic dispersion, and diffusion. Discretization is performed by the finite-difference method using centered or backward weighting in the time and space domains. Matrix solution is performed either by Gaussian elimination or by two-line successive over-relaxation. SWIFT/486 handles a variety of boundary conditions and source terms for both the porous and fractured media including 
prescribed head, temperature, and brine concentration; prescribed flux of fluid, heat, brine and mass; wellbore injection/production; aquifer influence function; waste leach radionuclide submodel for waste repository nuclides and heat; and free water surface with recharge.

\section{System Requirements}

- Intel 80486DX/Pentium based computer

- $\quad$ SURFER $®$ for postprocessing

- DOS 5.0 or higher

- $8 \mathrm{Mb} \mathrm{RAM}$

\section{TRACR3D}

Version 1.0

Developers: B.J. Travis (Los Alamos National Laboratory)

TRACR3D is a 3D implicit (for flow)/semi-implicit (for transport) finite difference model for simulation of transient two-phase flow of water and air, and of nonconservative multi-component transport in deformable, heterogeneous, watersaturated or variably-saturated, reactive porous and/or fractured media. Flow of liquid and gas is coupled using Brooks and Corey expressions for relative hydraulic conductivity of liquid and gas. Transport processes include advection, dispersion, sorption, and decay. The model can handle simple, steady-state, 1D, single-phase problems to complex, transient, two-phase flow and tracer transport (EPA 1994; Travis, 1984).

System Requirements

- Intel $386 / 486$ based computer

\section{$\mathrm{VS} 2 \mathrm{D} / \mathrm{T}$}

Version 2.0

Developer: R.W. Healy (U.S.G.S)

VS2D is a 2D finite difference code for simulation of cross-sectional or cylindrical variably saturated flow in porous media (IGWMC, 1995). The model will consider nonlinear storage, nonlinear conductance, sink terms, infiltration, evapotranspiration, seepage faces, and boundary conditions. Nonlinear conductance terms, boundary conditions, and sink terms are linearized implicitly. Nonlinear storage terms are linearized by an implicit Newton-Raphson method. Relative hydraulic conductivity is evaluated at cell boundaries by using full upstream weighting, the arithmetic mean, or the geometric mean of values of adjacent cells. Saturated hydraulic conductivities are evaluated at cell boundaries by using distance weighted harmonic means. The 
linearized matrix equations are solved using the strongly implicit method. Nonlinear conductance and storage coefficients are represented by closed-form algebraic equations or interpolated from tables. The model includes a preprocessor, PREVS2DT, and a post-processor, POSTVS, which reformats output into a form suitable for contouring with commercial packages. VS2D/T is a solute transport code that is used with VS2D. It is based on a finite difference approximation of the advection-dispersion equation for a single species. Modeling options include firstorder decay, equilibrium adsorption using the Freundlich or Langmuir isotherms, and ion exchange.

\section{System Requirements}

- Intel 80386/80486 based computer

- DOS 3.0 or higher

- $4 \mathrm{Mb}$ RAM

- math coprocessor

- about $2.5 \mathrm{Mb}$ free disk space

\section{Recommended Groundwater Flow/Contaminant Transport Codes}

Table 2.1 presents a summary of the attributes of the groundwater flow and transport codes that have been reviewed in this report. In addition to the criteria described in the introduction to this report, the following attributes are considered to be important for groundwater flow and transport models recommended for use by the UMTRA project: 1) 2D or 3D flow and transport, 2) saturated flow, 3) finite difference or finite element method of solution, 4) transient and steady state analysis, 5) confined and unconfined aquifer analysis, 6) heterogeneous and anisotropic media, 7) .multiple sources and sinks, 8) advection, dispersion, and reaction transport processes, and 9) adsorption and first-order decay reaction types. Based on these criteria, MODFLOW and MT3D are considered to be the codes that will best meet the needs of the UMTRA project for groundwater flow and contaminant transport modeling. These codes are recommended for the following reasons:

1. MODFLOW can simulate both $2 \mathrm{D}$ and $3 \mathrm{D}$ flow and all aquifer conditions that are expected to be encountered at UMTRA sites. MODFLOW can also be used in conjunction with MODPATH, a particle tracking program.

2. MT3D can model contaminant transport by advection, dispersion, and chemical reaction in three dimensions. It is designed to receive input directly from MODFLOW.

3. Preprocessors and post-processors are available to assist the user in assembling input data and viewing output data. 
4. MODFLOW and MT3D are used extensively in industry and throughout the DOE complex.

Disadvantages to the use of these codes include the following:

1. MT3D may incur mass balance problems attributed to the Method of Characteristics, an algorithm built into the code.

2. MT3D can only model a limited number of chemical reactions including adsorption, first order decay/production, mixing, and biodegradation.

Other flow and transport models to consider are FTWORK, SWIFT/486, and RAND3D. SWIFT/486 should be considered because of its ability to model decay chains; FTWORK because it provides a direct finite-difference solution to transport in the event that the Method of Characteristics scheme in MT3D has mass balance problems; and RAND3D because it provides a particle-tracking solution to transport without potential mass balance problems and it works with MODFLOW equally well as MT3D. Still other models to consider are HYDROGEOCHEM and, although it is only 2D, LEHGC. Both of these codes, which are currently under development, could potentially be used for modeling groundwater flow and contaminant transport at UMTRA sites. LEHGC, may be particularly useful for simulating chemical reactions that cannot be handled by MT3D, RAND3D, or FTWORK. However, these models will require further development before they can be used by the UMTRA groundwater restoration project. 


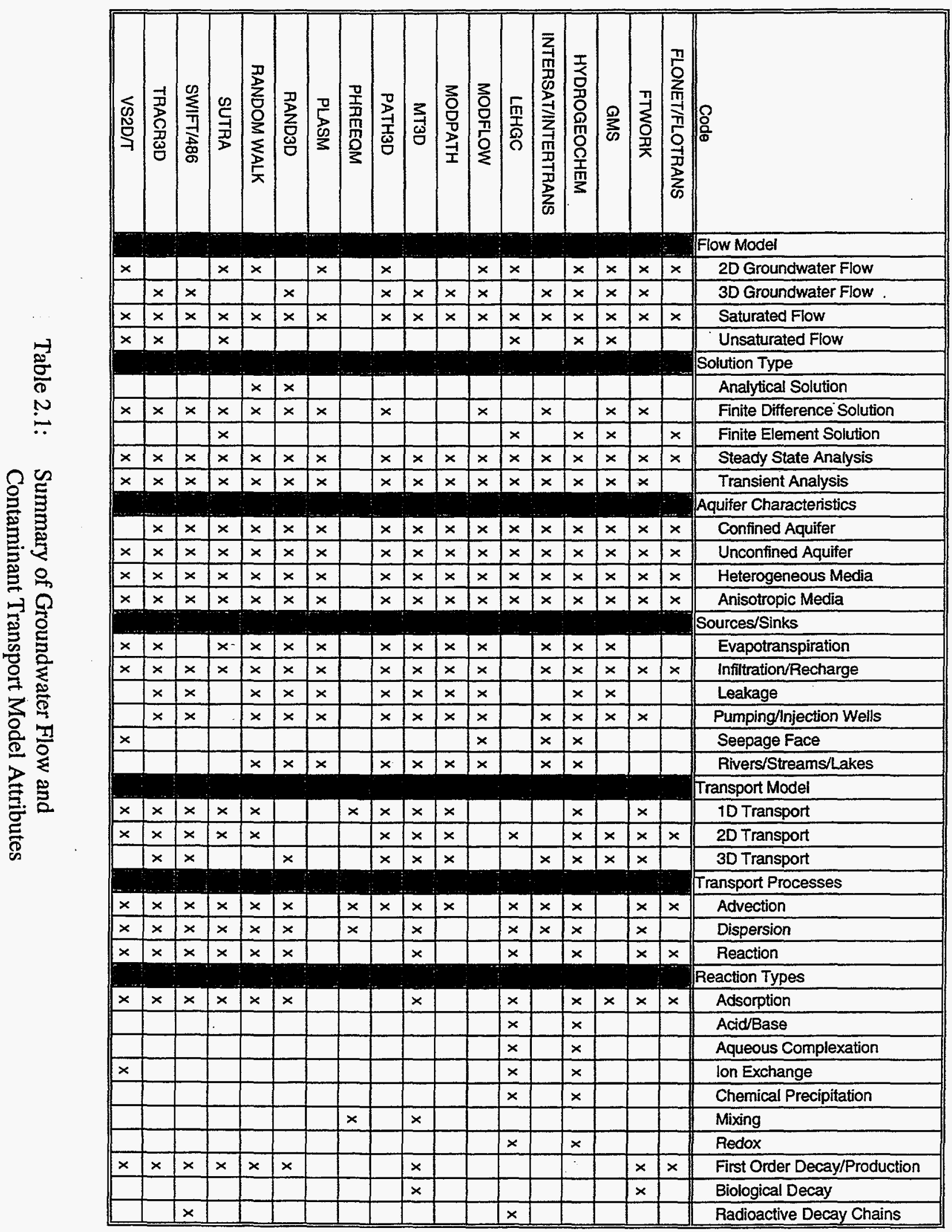


(this page left blank) 


\section{Section 3 \\ Hydrogeochemical Modeling Codes}

\section{A. Overview}

Chemical speciation of the elements in groundwater solutions may be performed with hydrogeochemical codes. The speciation of elements in UMTRA groundwaters is important to determine whether contaminants occur as cations or anions or in complexes. This information can be used to determine if hazardous constituents will be adsorbed by the exchange complex. For example, under high $\mathrm{Eh}$ and low $\mathrm{pH}$ conditions, uranium exists as the uranyl $\left(\mathrm{UO}_{2}{ }^{2+}\right)$ cation. However, at a higher $\mathrm{pH}$, uranium will form complexes with carbonate and sulfate ions [i.e., $\mathrm{UO}_{2}\left(\mathrm{CO}_{3}\right)_{3}{ }^{4-}$. While the uranyl ion may adsorb strongly on the cation exchange complex, the carbonate and sulfate complexes will not. The attenuation of uranium is, therefore, strongly dependent on solution chemistry and speciation. Numerical geochemical modeling can be important in determining the transport of hazardous constituents in UMTRA groundwater. In the case of natural attenuation, geochemical modeling can be used to determine the equilibrium species and their potential for attenuation along a flow path.

Hydrogeochemical codes have been developed to model solute/mineral and solute/solute reactions that occur in groundwater including dissolution/precipitation, oxidation/reduction, sorption, ion exchange, and, in some cases, radioactive or biological decay. There are two general types of hydrogeochemical models: inverse models and forward models. Inverse modeling is used to identify reactions which could have occurred along a flow path when conditions are known at each end of the flowpath. Forward modeling is used to specify reactions starting with a given water analysis. In addition to inverse and forward modeling, hydrogeochemical models are also able to speciate a water sample when given the total concentration of elements in solution along with the $\mathrm{pH}$ and $\mathrm{Eh}$ (or redox couples) of the solution.

There are a large number of hydrogeochemical models now available. Since these models use an equilibrium approach to the modeling of geochemical reactions (as opposed to a kinetic approach), they do not solve differential equations. Instead, the equilibrium processes are represented by a large number of algebraic equations, which are solved simultaneously. These models will likely be extensively used to implement the observational approach to groundwater restoration at UMTRA sites. 
Several models which have the potential to meet the needs of the UMTRA project are described below:

\section{$\mathrm{EQ} 3 / 6$}

\section{Version 7.2}

Developers: T.J. Wolery (Lawrence Livermore National Laboratory)

EQ3/6 is a software package for geochemical modeling which includes several components; 1) EQ3NR, a speciation and solubility code, 2) EQ6 a reaction path code which models water/rock interaction or fluid mixing in either a pure reaction progress mode or a time mode, 3) EQPT, a data file preprocessor, 4) EQLIB, a supporting software library, and 5) five supporting thermodynamic data files. The codes were written in FORTRAN and were developed for the UNIX operating system (Wolery, 1979). Recently, a PC version has been developed. EQ3/6 is considered to be the proprietary geochemical modeling code of the U.S. Department of Energy. The EQ3/6 code accesses a database containing thermodynamic properties for 78 elements, 862 aqueous species, 886 minerals, and 76 gases. This database contains 57 aqueous uranium species and 160 uranium-bearing minerals, which constitutes the most complete database available for modeling the behavior of uranium in natural waters. EQ3 is the portion of the code that calculates initial speciation of the water from user-specified concentration data and computes saturation indices of minerals. The EQ6 portion of the code performs reaction path modeling which simulates a sequence of thermodynamic equilibrium problems in reacting systems consisting of water and minerals (or other solids). Along each step of the reaction path, EQ6 computes the precipitation and dissolution of minerals based on mass action expressions for solubility equilibrium with water. Thus EQ6 differs from other codes in that it allows supersaturated minerals to precipitate and undersaturated minerals to dissolve. There are several limitations to EQ3/6. First, a limited number of organic constituents can be modeled which may underestimate the concentrations of inorganic contaminants if organic complexation occurs. Second, the solid phases are considered to be stable minerals instead of less stable amorphous phases which may actually exist. Third, dissolution and precipitation are considered to be instantaneous without consideration for kinetics and, fourth, adsorption processes are not considered.

System Requirements

- Intel 80486 based computer

- DOS 5.0 or later 
- Windows 3.1 or later

- at least $20 \mathrm{Mb}$ of hard disk space

\section{MINTEQA2}

Version 3.11

Developers: J.D. Allison, D.S. Brown, and K.J. Novo-Gradac (U.S. EPA)

MINTEQA2 is a geochemical equilibrium speciation model for dilute aqueous systems. MINTEQA2, which is sponsored by EPA, originated as MINTEQA1, a code based on WATEQ (Truesdell and Jones, 1974). The model can be used to calculate mass distribution between dissolved, adsorbed, and multiple solid phases and gas phases. A mineral can be specified as being in equilibrium with the solution, and either subject to dissolution if conditions warrant, or not subject to complete dissolution. The database for MINTEQA2 contains 39 elements, 456 minerals, 16 gases, and 8 organic ligands. The database is external to the code and can be modified by the user. The code acts in a temperature range from $0-100^{\circ} \mathrm{C}$. An interactive preprocessor, PRODEFA2, is included with MINTEQA2 (IGWMC, 1995).

\section{System Requirements}

- Intel 80i86 based computer

- $640 \mathrm{~Kb}$ RAM

- a high density floppy disk drive

- DOS 3.0 or higher

- math coprocessor optional

- at least $2 \mathrm{Mb}$ free disk space

\section{NETPATH}

\section{Version 1.2.2}

Developers: L.N. Plummer, E.C. Presemon, and D.L. Parkhurst (U.S.G.S)

NETPATH is an interactive program for modeling net geochemical mass-balance reactions between an initial and final solution along a flow path and is generally used for inverse modeling (Plummer et al., 1991). NETPATH can also compute the net geochemical reactions and the mixing proportion of two initial waters to account for the composition of a final water solution. Every possible set of geochemical reactions are computed for a given set of initial and final waters and mineral phases chosen by the user. NETPATH considers mineral dissolution, mineral precipitation, ion exchange, isotopic exchange, redox reactions, evaporation or dilution, mixing of waters, and isotopic evolution. NETPATH is useful for interpreting geochemical reactions, mixing proportions, evaporation and/or dilution of waters, and mineral 
mass transfer in the chemical and isotopic evolution of natural and environmental waters. An interactive preprocessor, DB, is included with NETPATH (IGWMC, 1995).

System Requirements

- Intel $80 \mathrm{i} 86$ based computer

- DOS 3.0 or higher

- 640 Kb RAM

- math coprocessor optional

\section{PHREEQE}

Version 2.1

Developers: D.L. Parkhurst, D.C. Thorstenson, and L.N. Plummer (U.S.G.S)

PHREEQE is a geochemical modeling code that is based on an ion pairing aqueous model (Parkhurst et al., 1980). The model, which is written in FORTRAN, can simulate the mixing of two or more solutions, titrations, solubility, irreversible reactions, reaction paths, and redox reactions. It can be used to investigate chemical reactions, predict the fate of inorganic constituents, and determine the speciation of a solution. This model is primarily a forward modeling code. PHREEQE can calculate $\mathrm{pH}$, redox potential, and mass transfer as a function of reaction progress and can compute solution composition in equilibrium with multiple phases. The aqueous model database is user-definable and is exterior to the computer code. PHREEQE also includes an interactive pre-processor PHRQINPT which produces an input file for the model (IGWMC, 1995). Although this model has been widely used for many years, it has several limitations. The thermodynamic data in the standard database has never been evaluated for adequacy, completeness, or consistency. The standard database also only contains 22 elements. Many contaminants of concern in UMTRA groundwater (such as uranium, arsenic, vanadium, etc.) would have to be added by the user. Also, the code does not model surface complexation and ion exchange reactions and is limited to relatively low ionic strength solutions $(I<0.7)$.

\section{System Requirements}

- Intel 80i86 based computer

- DOS 3.0 or higher

- 640 Kb RAM

- math coprocessor optional 


\section{PHREEQC}

Version 1.0

Developers: D.L. Parkhurst (U.S.G.S)

PHREEQC is a revised version of PHREEQE and is written in the $\mathrm{C}$ programming language. It retains all of the capabilities of PHREEQE but also contains an enhanced speciation code, the ability to model surface complexation and ion exchange reactions, the ability to model interactions between groundwater and gas bubbles, 1D advective transport, and inverse modeling. This model may be used to investigate chemical reactions, predict the fate of inorganic constituents, speciate a solution, find stable phase assemblages, perform inverse modeling, and conduct simple advective calculations. This model also has some limitations. The aqueous model is limited to relatively low ionic strength $(\mathrm{I}<0.7)$, the thermodynamic data has never been evaluated for adequacy, completeness or consistency, and surface complexation and exchange reactions need to be determined on a site by site basis. The database is completely user-definable and external to the computer code. However, like PHREEQE, many contaminants of concern in UMTRA groundwaters (such as uranium) are not included in the standard database and would have to be added by the user. This model was written with the added capability of using the WATEQ4F database which does contain many additional elements.

System Requirements

- Intel 80i86 based computer

- DOS 3.0 or higher

- $640 \mathrm{~Kb}$ RAM

- math coprocessor optional

\section{WATEQ4F}

Version 2.0

Developers: J.W. Ball, and D. Kirk Nordstrom (U.S.G.S)

WATEQ4F is a chemical equilibrium model based on the original WATEQ model written in 1973 (Truesdell and Jones, 1974). WATEQ was originally written in PL/1, whereas WATEQ4F is written in FORTRAN. WATEQ4F is limited to the modeling of chemical speciation. It models thermodynamic speciation of major and important minor inorganic ions and complex species in solution for a given water analysis and measured values of temperature, $\mathrm{pH}$, and redox potential. The latest version of WATEQ (Version 2.0) includes several revisions to the thermodynamic database, including the addition of selenium and uranium. WATEQ4F includes a preprocessor, 
WQ4FINPT, which allows the user to create input files for the model (IGWMC, 1995).

\section{System Requirements}

- Intel 80386/80486 based computer

- DOS 3.0 or higher

- $640 \mathrm{~Kb}$ RAM

- $2 \mathrm{Mb}$ of free disk space

\section{B. Recommended Hydrogeochemical Modeling Codes}

Table 3.1 presents a summary of the attributes of the hydrogeochemical model codes that have been reviewed in this report. The attributes that are considered to be important for hydrochemical codes recommended for use by the UMTRA project include: 1) speciation and forward modeling capabilities, 2) inclusion of an extensive database for contaminants typically found at UMTRA sites, and 3) capability for multiple reaction types including adsorption, acid/base, aqueous complexation, oxidation/reduction, and radioactive decay. Based on these criteria and the information presented in the introduction to this report, the EQ3/6 hydrogeochemical model is recommended for use by the UMTRA groundwater restoration project. This code is recommended for the following reasons:

1. The EQ3/6 database contains extensive thermodynamic data for the less common elements (such as uranium) that are contaminants of concern in UMTRA groundwaters.

2. $\mathrm{EQ} 3 / 6$ has been extensively validated using standard geochemistry problems such as the speciation of seawater (Nordstrom et al., 1979) and has been compared to other codes in benchmark studies (INTERA, 1983; Kincaid and Morey, 1984; Nordstrom et al., 1979).

3. $\mathrm{EQ} 3 / 6$ is used extensively in industry and throughout the DOE complex.

The major disadvantage to the use of EQ3/6 is that this model does not include all reaction types which may be encountered at UMTRA sites such as adsorption and radioactive decay. Other models that could be considered for use are MINTEQA2 and PHREEQC (with the WATEQ4F database). 


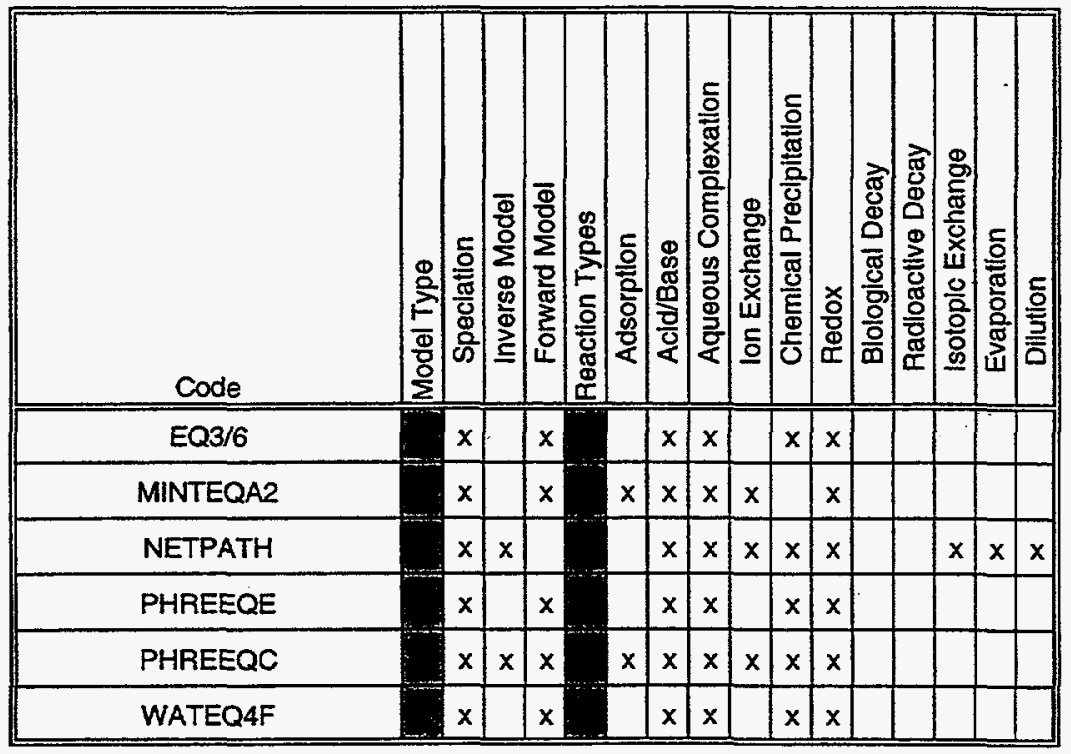

Table 3.1: Summary of Hydrogeochemical Model Attributes 
(this page left blank) 


\section{Section 4 \\ Pump and Treat Optimization Modeling Codes}

\section{A. Overview}

Groundwater restoration by pump and treat systems has been criticized for being too expensive and time-consuming. Although other technologies for groundwater restoration are being developed, pump and treat systems remain the only proven method for widespread contamination. The inability of pump and treat systems to achieve aquifer remediation within reasonable time frames can be attributed to several factors, including: 1) the tendency of many contaminants to sorb on formation materials which is manifested by the slow release of contaminants from lowpermeability materials, 2) geologic complexity, which can be identified through detailed characterization of the porous media, 3) the failure to apply dynamic well field management techniques, and 4) high operating and maintenance costs. Most of these shortcomings can be overcome by better planning, design and implementation of systems which incorporate some or all of the following: 1) detailed characterization of the aquifer and other porous media, 2) use of computer-aided data interpretation and decision support tools, 3) removal of the contaminant source, 4) initial design for plume containment and source remediation, 5) phased installation of the pumping well field, 6) detailed monitoring of the system, 7) active ongoing reevaluation of the operating well field, 8) reinjection of treated groundwater to speed flushing of the contaminants, and 9) setting of appropriate cleanup levels and pump and treat objectives (Hoffman, 1993).

Background information that can play an important role in the selection and recommendation of pump and treat optimization codes includes:

1. Basic concepts and principles of contaminant hydrogeology.

2. Data Quality Objectives/Data Requirements.

3. Groundwater restoration approach which usually consists of:

- Selecting an appropriate remedial action. (This can be a combination of more than one remediation technology).

- Defending the selected remedial action before the regulatory agencies, if required.

- Designing the required monitoring network.

- Designing the components of the remedial action system. 
- Construction and operation of the remedial action system.

4. Groundwater restoration system design verification including utilization of suitable computer codes.

\section{B. Pump and Treat System Optimization Strategies}

In addition to the various factors affecting pump and treat systems described above, optimization of pump and treat systems usually includes the following:

1. Simulation - simulation analysis alone can be used for simple systems or it can be used for scoping and screening alternatives prior to the application of optimization procedures for more complex systems.

2. Simulation Plus Optimization - optimization of an engineering system involves a determination of the optimal values for a set of decision variables for the system. Optimization is defined with respect to a specified objective function and is subject to a set of constraints (Gorelick et al., 1986).

3. Simulation Plus Decision Analysis - decision analysis is the process by which the best values for a set of decision variables can be obtained and by which the best alternative from a discrete set of alternatives can be obtained.

4. Design Optimization - combining simulation models and optimization techniques can, under certain circumstances, lead to design optimization.

Pump and treat optimization codes are designed to assist designers in implementing some or all of these steps. Most notably, these codes can assist engineers and field personnel in selecting optimal locations for extraction and injection wells and make it easier to evaluate and make changes in the restoration process as it progresses. To date, most of these codes have been used largely for restoration projects involving organics, and have not been used extensively for projects involving heavy metal and radionuclide contamination. However, some codes can be used to design pump and treat systems for restoration of aquifers contaminated with metals and radionuclides.

In line with the objective of this report (as described above), it is assumed that information required for input to pump and treat optimization codes is available from other efforts/documents within the UMTRA project. Some pump and treat optimization codes that could potentially meet the needs of the UMTRA groundwater restoration project are described below. 


\section{AQMAN3D}

Version 1.0

Developer: L.J. Lefkoff and S.M. Gorelick (U.S. Geological Survey)

$\mathrm{AQMAN} 3 \mathrm{D}$ is a $3 \mathrm{D}$ aquifer management program which may be used to determine the distribution of pumping and/or recharge that minimizes or maximizes some userspecified objective function while satisfying user-specified constraints on groundwater hydraulic conditions. AQMAN3D provides a link between the U.S. Geological Survey modular 3D finite-difference groundwater flow model, MODFLOW, and any standard optimization program that uses MPS (Mathematical Programming System) input format. The program creates the input fields that may be used by the optimization program. AQMAN3D creates a datafile written in MPS format that contains all the hydrologic information and management objectives needed by an optimization program to solve the aquifer management problem. AQMAN, a 2D version of this model, is also available (Appel and Reilly, 1994).

\section{System Requirements}

- Intel 386/486 based computer

\section{FLOWPATH}

\section{Version 5.0}

Developer: Waterloo Hydrogeologic Software, Waterloo, Ontario, Canada

FLOWPATH is a 2D, mesh-centered, finite difference, steady-state groundwater flow model with particle tracking (IGWMC, 1995). This model can be used to calculate wellhead protection zones, hydraulic heads, groundwater velocities, time-related pathlines, capture zones, water balances, and steady-state drawdown. Physical processes that can be modeled include confined, leaky confined, or unconfined flow in heterogeneous and anisotropic porous media. The model can account for pumping and injection wells, spatially variable groundwater recharge and evapotranspiration, variable leakage characteristics of underlying and overlying aquitards, and interaction between groundwater and surface-water bodies. Groundwater pathlines are calculated using the particle tracking method. FLOWPATH uses reverse distance interpolation and Euler integration to move particles along a pathline (Anderson and Woessner, 1992). The model includes a graphical user interface for data input and output. FLOWPATH is considered suitable for design of pump and treat systems, evaluation of containment schemes, and delineation of wellhead protection areas. 
System Requirements

- Intel 386/486 based computer

- DOS 3.1 or higher

- 4 Mb RAM

- math coprocessor

- EGA or VGA graphics

- about $4 \mathrm{Mb}$ free disk space

- Microsoft mouse or compatible

\section{MODMAN}

Version 3.02 (1/94)

Developers: R.M. Greenwald (GeoTrans, Inc.)

MODMAN is an optimization program designed to link with the USGS MODFLOW code. MODMAN, in conjunction with the proprietary optimization software LINDO, answers the following groundwater management questions: 1) where should pumping and injection wells be located, and 2) at what rate should water be extracted or injected at each well. The optimal solution maximizes or minimizes a user-defined objective function and satisfies all user-defined constraints. For example, the total pumping rate from all wells may be maximized while constraints might include upper and lower limits on heads, gradients and pumping rates. Several objective functions and constraints are available to the user. The MODMAN program includes a special version of the MODFLOW program. Calibrated 2D or 3D MODFLOW input files are required to run MODMAN (IGWMC, 1995).

\section{System Requirements}

- Intel 80386/80486 based computer

- DOS 5.0 or higher

- Windows 3.0 or higher

- a high-density floppy disk drive

- about $3 \mathrm{Mb}$ disk space

- math coprocessor

\section{OPTP/PTEST}

\section{Version $1.0(10 / 86)$}

Developers: G.N. Paudyal and A. Das Gupta (Asian Institute of Technology)

OPTP/PTEST is a software package consisting of two programs for determining optimal well discharge. PTEST computes the coefficients and exponent of the nonlinear drawdown equation using data from a step-drawdown test. OPTP computes the optimal discharge using single-variable constrained nonlinear programming algorithm (IGWMC, 1995).

\section{System Requirements}

- Intel $80 i 86$ based computer

- math coprocessor 


\section{PLANET}

Version 1.0

Developers: T.W. Canales, A.F.B. Tompson, J.P. Ziagos (LLNL); E.M. Nichols (Weiss Assoc.)

PLANET is a pump layout and evaluation tool. Within PLANET, a series of chemical transport simulations can be interactively designed and displayed to examine the migration of existing contaminant distributions in the saturated zone under natural conditions and various proposed extraction scenarios such as those conducted during remedial pumping. Recovery of such contaminants may be estimated by sequential use and substitution of various steady state flow fields, corresponding to pumping configurations, within a transport model. PLANET consists of three modules; 1) a calibrated flow model (MODFLOW), 2) a nonreactive version of a particle transport model (SLIM), and 3) a map-oriented graphical interface through which the user can view and direct progress of the simulation. The system facilitates visualization of contaminant distributions over time and enables the user to interactively manipulate extraction scenarios by adjusting well locations and pumping rates (Canales et al., 1992). The PLANET graphical user interface can simultaneously display a series of registered color overlays that includes a feature map of the site, computational grids, and the location of monitor, extraction, and injection wells. Extraction and injection wells can be added, deleted, adjusted, or relocated during the course of a simulation. Corresponding flow field adjustments can also be made. PLANET is an X-Windows based application that was developed for use on UNIX workstations.

System Requirements

- UNIX workstation

- $24 \mathrm{Mb}$ of RAM

- $30 \mathrm{Mb}$ of swap space

\section{Recommended Pump and Treat Optimization Codes}

Table 4.1 presents a summary of the attributes of the pump and treat optimization codes that have been reviewed in this report. Attributes that are considered important for pump and treat optimization codes recommended for use by the UMTRA project include: 1) groundwater flow modeling, 2) the capability to simulate pump and treat system design changes, and 3) the capability to include injection wells, extraction wells, and contaminant migration in the system design. Based on these criteria and 
information presented in the introduction to this report, the PLANET code is recommended for use by the UMTRA project for the following reasons:

1. PLANET can be used in conjunction with MODFLOW, a widely used groundwater flow model.

2. PLANET contains a map-oriented graphical interface through which the user can direct the simulation interactively.

3. In PLANET, extraction and injection wells can be added, deleted, adjusted, or relocated during the course of a simulation with corresponding adjustments to the flow field.

Other models that could be considered for use are AQMAN and AQMAN3D. Both of these codes are publicly available through the U.S. Geological Survey and provide objective decision analysis solutions to well-field design problems (rather than visual-based solutions).

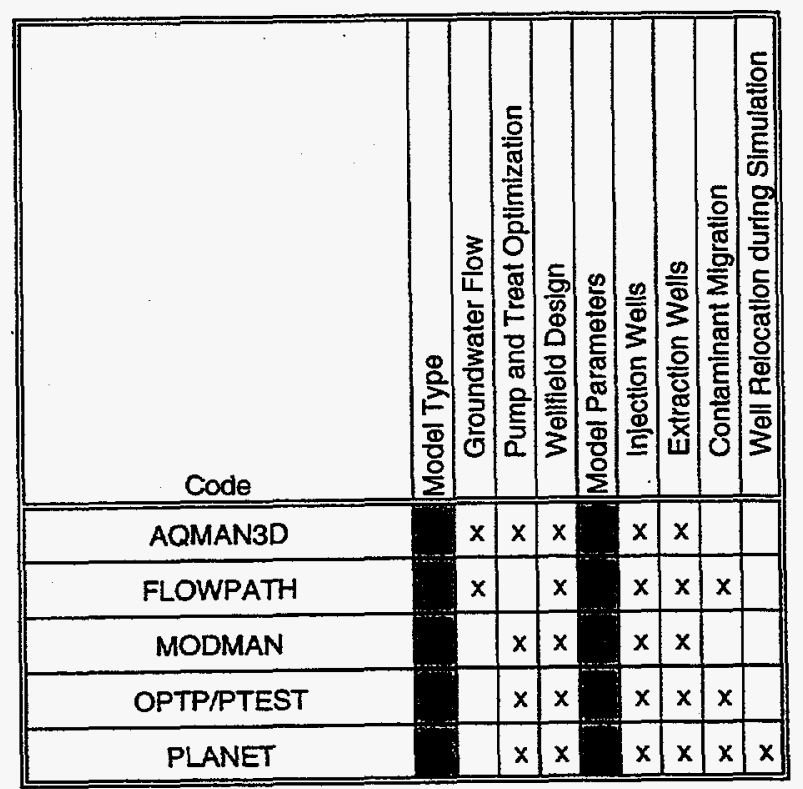

Table 4.1: Summary of Pump and Treat Optimization Model Attributes 


\section{Section 5 \\ Decision Support Tools}

\section{A. Overview}

Decision support tools can be used for several purposes. For this reason, several codes in this category will be recommended for use by the UMTRA project to implement the observational approach. In this section, four types of codes are surveyed, including: 1) decision support tools to perform remediation project cost estimation, 2) decision support tools to optimize the placement of monitor wells and borehole sampling locations, 3) decision support tools for performing risk assessments to quantify the uncertainty in risk to the public and the environment, and 4) decision support tools to visualize and display data.

\section{BOSS}

Version 1.0 (Beta Version)

Developers: Sandia National Laboratories

The Borehole Optimization Support System (BOSS) is a decision support tool intended to provide defensible information regarding the necessary number and location of monitor wells and boreholes to delineate the nature and extent of groundwater contamination beneath a waste site. The BOSS methodology comprises several steps. First, analytical and numerical models based on the physics of flow and transport are employed in a stochastic modeling scheme (i.e. Monte Carlo simulations). Many runs are made to quantify the uncertainty in the nature and extent of contamination. Second, the computer-generated output is compared to known concentrations within the plume, and the output is conditioned to these data. Next, a probability field describing expected plume distributions is generated from the stochastic output. Finally, a decision analysis methodology based on operations research methods is employed to determine the location of the next monitor well. This technology is intended to guide monitor well and borehole placement during characterization by providing overnight feedback to the site operator.

\section{System Requirements}

- Intel 80386/80486 based computer

$\underline{\mathrm{OR}}$

- Macintosh or Macintosh PowerPC
- Windows or Windows NT 


\section{CalTOX}

\section{Version 1.5}

Developers: California Environmental Protection Agency

CalTOX is a spreadsheet model for simulating the fate of and exposure to nonionized, organic chemicals at low concentrations. The model does not apply to chemicals released into soil less than one year. CalTOX is comprised of a multimedia transport and transformation model, an exposure scenario model, and uncertainty analysis. The multimedia transport model predicts the movement of a chemical between seven environmental compartments including air, water, three soil layers (ground-surface soil, plants, root-zone soil) sediment and plants. The model partitions the concentration of the chemical among the seven compartments and then determines chemical concentrations in various exposure media including the air-breathing zone, drinking water, food, and soil (ingestion, inhalation, and dermal contact). The exposure scenario converts the concentration to a dose intake using EPA default values. An uncertainty analysis component can perform Monte Carlo simulations. CalTOX can perform reverse dose calculations for determining soil cleanup goals, the output of which is sent to a spreadsheet. However, soil cleanup goals can only be calculated for one chemical at a time. Model soil types are limited and only include the "California" and "Sacramento" soils. More California soil types are slated to be added to the model but there are no plans to expand the model beyond the state of California (Block, 1995).

\section{System Requirements}

- Intel 80386/80486 based computer

- Windows 3.1

- modem

- $2 \mathrm{Mb}$ disk space on hard drive

- Microsoft Excel 4.0 for Windows or higher

$\underline{\mathrm{OR}}$

- Macintosh computer

- $2 \mathrm{Mb}$ disk space on hard drive

- Microsoft Excel 4.0 for Macintosh

\section{CURE}

Version 1.0 (under development)

Developers: Sandia National Laboratories and Delta Research, Inc.

CURE is a decision support tool that has been designed to aid decision makers in quantifying the total cost of remediation, including an assessment of cost uncertainty. Typically, remediation costs are simple point estimates without a rigorous measure of 
uncertainty. RCRA Corrective Measure Studies and CERCLA Feasibility Studies require assessment of cost for various potentially applicable remedial alternatives. Point estimates are usually developed using crude site characterization information, which leads to uncertainty in the estimate. Application of CURE would result in better cost estimates given limited site information, provide a more defensible estimate of contingency based on uncertainty, facilitate rapid cost assessment relative to other approaches, allow the capability of performing sensitivity analyses, and lead to more informed decisions for screening remedial alternatives while conducting Feasibility Studies. The code is formulated from three key elements: 1) the ENVEST module of the DOD's RACER (Remedial Action Cost for Environmental Restoration) with modifications to allow for uncertainty analyses, 2) a stochastic approach to estimating cost using the Monte Carlo/Latin Hypercube Sampling method, and 3) a sensitivity analysis method to assess the importance of ENVEST unit operation primary variables.

System Requirements

- Intel 80386/80486 based computer

- Windows 3.0 or higher

$\underline{\mathrm{OR}}$

- Macintosh or Macintosh PowerPC

\section{DSS}

Version 1.01

Developers: American Petroleum Institute

The American Petroleum Institute has developed the Risk/Exposure Assessment Decision Support System (DSS) as a risk assessment tool for sites contaminated with petrochemicals. Contaminant fate and transport models included in DSS are SESOIL (Seasonal Soil Compartment Model), Jury (unsaturated zone transport model), Cowherd (particulate emissions model), and AT123D (saturated zone transport model). DSS consists of four modules. Module 1 allows the user to develop a risk scenario wherein the user selects contaminants of concern, exposure routes, and the method of estimating receptor point concentrations. Twenty-five chemicals are available for selection but only five may be selected at one time. There are six exposure routes including drinking water, soil ingestion, dermal contact with soil, inhalation of soil emissions, and inhalation and dermal contact during showers. Based on the exposure routes that are chosen, the user can select the appropriate method for determining groundwater concentrations. For example, the user may select AT123D, 
Jury followed by AT123D, or SESOIL followed by AT123D. Module 2 is used to provide input data for the fate and transport models. Physical and chemical properties of listed chemicals are provided as part of the database. Module 3 is the chemical intake and risk calculation module which estimates dose and risk. Calculations are based on such data as body weight, exposure frequency, slope factor, and reference dose. Default values, which may be modified by the user, are provided in the database. Module 4 is a risk presentation module. It allows use of Excel spreadsheets to present report-ready tables and charts of dose, risk and hazard indices. Users can present results using a deterministic output or an uncertainty-based interpretation using Monte Carlo simulation (Block, 1995).

System Requirements

- Intel 80386 or higher based computer

- Windows 3.1 or higher

- math coprocessor

- at least $4 \mathrm{Mb}$ RAM

- VGA or Super VGA monitor

- $6 \mathrm{Mb}$ free disk space

- Microsoft Excel 4.0 for Windows or higher

\section{ERMA Data Manager}

Version 6.0

Developers: Intergraph Corporation

ERMA (Environmental Resource Management Applications) presents a UNIX-based system of graphics and relational database applications for data management, engineering, GIS, and analytical software for assessing, modeling, and monitoring environmental projects. Data Manager is the data management and analysis component of ERMA. This code integrates advanced 3D graphics capabilities and data management tools with personal productivity tools, such as spreadsheets and word processors. The code features an open, highly flexible database that supports a wide range of project data and formats. These include sample information, digital maps and cross-sections, grid models, scanned aerial photographs, boring logs, construction drawings, regulatory information, and scanned documents. Nongraphical data are stored in the user's choice of relational databases (Sybase, Oracle, Ingres, DB2, or Informix) and graphical data are stored in a published standard format. Functions are also provided for loading ASCII data and for easily accessing, querying, and updating database information. An interactive graphical interface supports rapid database query, graphic map creation, and custom report generation. 2D and 3D maps can be created or updated by extracting sample, well, or other 
location-dependent information. This capability allows the user to readily evaluate, visualize, and report on spatially and temporally complex information within a full $3 \mathrm{D}$ graphics environment.

System Requirements

- Intel 80486 or higher based computer

- $\quad 24 \mathrm{Mb}$ of memory

- $500 \mathrm{Mb}$ disk drive

\section{ERMA Site Geologist}

Version 6.0

Developers: Intergraph Corporation

ERMA (Environmental Resource Management Applications) presents a UNIX-based system of graphics and relational database applications for data management, engineering, GIS, and analytical software for assessing, modeling, and monitoring environmental projects. Site Geologist is the ERMA application which assists the user in generating, interpreting, and managing subsurface information, borelogs, cross-sections, and fence diagrams. It generates $2 \mathrm{D}$ and 3D subsurface drawings by reading subsurface information stored in a relational database and enables subsurface horizons to be interpreted interactively based on information posted from the database. Cross-sections containing vertical or non-vertical wells can be created. Site Geologist enables users to access virtually any depth-related data, including well paths, well data, and geological feature data. It allows the incorporation of both original and interpretive data and the interactive modification of either as they pertain to the geological site model. The code provides 3D viewing and analysis capabilities. 3D cross-sections rotated and viewed in any orientation. Also, a variety of data types, including borehole, well and sample data, geologic maps, hardcopy contour maps, and XYZ data files can be simultaneously and interactively displayed. Site Geologist interfaces to popular contouring packages and personal productivity tools such as word processors and spreadsheets. The code is also integrated with other ERMA products such as Data Manager.

\section{System Requirements}

- Intel 80486 or higher based computer

- $\quad 24 \mathrm{Mb}$ of memory

- $500 \mathrm{Mb}$ disk drive 


\section{MEPAS}

Version 3.1

Developers: Pacific Northwest Laboratory

MEPAS (Multimedia Environmental Pollutant Assessment System), is based on standard physics-based risk estimation methods involving a source term, transport, exposure, and consequence models. It is a fully coupled assessment model developed for the DOE to estimate public health risks for ranking contaminated sites. The model was developed to cover a wide range of potential problems and regulatory issues at DOE sites in various stages of characterization. It can be used to 1) simulate the temporal and spatial distribution of contaminants within each environmental medium, 2) temporally transfer contaminants at the interface of environmental medium, 3) provide consistent health impacts from a source term to exposure analysis for a large number of problems and sites, 4) provide detailed guidance on the implementation of the analysis, 5) supply the user with a fully integrated and coupled chemical data base for 397 organic and inorganic chemicals and radionuclides, and 6) interface with the user through a user-friendly shell. Using MEPAS, contaminant source-to-receptor analyses can be conducted through all the major transport pathways (i.e., air, groundwater, overland, and surface water), and exposure routes (i.e., inhalation, ingestion, dermal contact, and external exposure). The waterborne components are linked through temporally varying contaminant-flux boundary conditions, while the linkage between water borne components and exposure routes is made through temporally varying water concentrations at receptor locations. The linkage between the atmospheric component and exposure routes is based on air concentrations and ground deposition factors, providing spatial variation of ground and air concentrations surrounding the site. In addition, each of the components has been linked such that the user-friendly shell only selects the appropriate subset of transport pathways and exposure routes necessary to describe the site-specific conditions the user wishes to evaluate. The latest release of MEPAS is a major update with expanded functionality for remediation applications.

System Requirements

- IBM Compatible PC DOS System 


\section{PLUME}

\section{Version 1.0}

Developers: R. Johnson (Argonne National Laboratories)

PLUME is an interactive, geostatistically-based, decision support tool designed to assist in the selection of sampling locations for delineating the extent of site contamination. PLUME allows the integration of "soft" information regarding plume location (such as non-intrusive survey data, historical records, and transport modeling results) with hard sampling data to form a conceptual image of contamination extent. PLUME uses a combination of Bayesian and spatial statistics to measure the potential impact of additional sampling points and to search for the next set of sampling points that contribute most to plume definition. PLUME can assist technical staff in the location of vertical and directionally drilled boreholes, and in the selection of sampling locations along such boreholes. PLUME can reduce characterization costs by eliminating unneeded samples, by optimally placing new samples, and providing measures that can be used to decide when enough data has been collected. PLUME can select new vertical and/or directionally drilled boreholes that would have the greatest impact on the uncertainty associated with contaminant extent. PLUME can also estimate the value additional sampling data. PLUME includes statistical measures of contaminant extent, such as estimates of volumetric contamination and lateral extent. The generic version of PLUME allows data import and export between PLUME and Geo-EAS, a public domain kriging package developed by the EPA, and XDataSlice, a public domain 3D visualization package developed by the Software Tools Group at the National Center for Supercomputing Application at the University of Illinois. The commercial version of PLUME also includes direct data exchange links with SitePlanner ${ }^{\mathrm{TM}}$ and $\mathrm{Xess}^{\mathrm{TM}}$ (ANL, 1994).

\section{System Requirements}

- Sun SparcStation (IPC, IPX, Sparc2, Sparc10, etc.)

- Sun OS 4.1.x

- $32 \mathrm{Mb}$ of RAM

OR

- Intel 486 based computer

- $32 \mathrm{Mb}$ of RAM
- OpenWindows 2.0 or higher

- $5 \mathrm{Mb}$ of disk space

- SCO Unix

- $5 \mathrm{Mb}$ of disk space 


\section{Précis}

\section{Version 1.1.3}

Developers: Sandia National Laboratories

Précis is a computer code designed to aid operable unit leaders, responsible parties, stakeholders, and regulators in establishing concentration thresholds for contaminants in soils, evaluating the potential human health risk a site poses to the public, as well as prioritizing site characterization needs. The Précis code uses probabilistic risk assessment methodology to aid in the decision making process regarding site disposition (e.g., risk, action levels, Data Quality Objectives [DQOs]). The code is based on several key elements: 1) a modified version of DOE's RESRAD code, to include radionuclides as well as hazardous constituents (e.g., VOCs and metals), 2) a stochastic approach to estimating risk using a Monte Carlo/Latin Hypercube sampling method to quantify uncertainties in risk and soil concentration thresholds, and 3) a sensitivity analysis method to prioritize the site characterization needs based on the relative importance of a parameter to the uncertainty in risk. Précis is intended to be used to quantify the uncertainty in human health risk. Nine environmental pathways are available for simulation of contaminant transport to a receptor. Both hazardous and radioactive constituents are accounted for in the analysis. Many realizations are performed to translate the uncertainty in the input parameters in the code into the uncertainty in risk. Each realization also yields an estimate of the soil concentration threshold based on a specified acceptable risk.

System Requirements

- Macintosh or Macintosh PowerPC

$\underline{\mathrm{OR}}$

- Intel 80486 based computer

- Windows or WindowsNT

\section{RACER}

\section{Version 3.0}

Developers: Delta Research, Inc.

The Remedial Action Cost Estimation and Requirements (RACER) System has two components. The Remedial Action Assessment System (RAAS) allows the user to identify feasible remediation technologies based on consideration of contaminants, affected media, risk, and applicable or relevant and appropriate requirements (ARARs). ENVEST is the cost engineering component and can be used to estimate characterization costs (the RCRA Facility Investigation and Corrective Measures 
Study) and remediation costs (corrective measures design and corrective measures implementation). ENVEST is also applicable to sites regulated under the Comprehensive Environmental Response, Compensation, and Liability Act (CERCLA). Corrective measures design costs are estimated as a percentage of corrective measures implementation costs. There are nine technology categories corresponding to varying levels of design complexity. Model defaults, which can be overridden by the user, range from 10.1 percent for a complex design for treatment of soils and sludge to 3 percent for an expedited pump-and-treat design. There are a total of 35 separate corrective measures implementation modules, corresponding to 35 unique remediation technologies. Included are various technologies for containment, removal, and in-situ and ex-situ treatment of soil and water. There are also 36 site work and utilities modules. ENVEST is modeled on pre-defined engineering relationships that link parameters to detailed assembly quantities. Assembly quantities are then priced using a resident unit-cost database. There are two categories of parameters used in each cost module, required and secondary. Required parameters that impact the site-specific engineering design and values must be specified. If there is sufficient project definition, the user may also specify secondary parameters; otherwise, the model will provide default values. ENVEST calculates quantities of assemblies composed of labor, material, and equipment items based on the parameter values and the engineering design and assumptions implicit in the model. Direct costs for assembly quantities are calculated using the U.S. Army Corps of Engineers' Unit Price Book (UPB). The unit costs for labor, material, and equipment items are based on construction performed in Atlanta, Georgia. Location factors, resident within ENVEST, can be applied to labor, material, and equipment to adjust for work in other locations. Unit costs for labor and equipment can also be adjusted for productivity based on the safety level (e.g., the amount of personal protective equipment needed to ensure worker safety). The user can override unit costs and quantities as well as productivity factors where site-specific information is available. The ENVEST database does not have unit costs for radioactive and mixed wastes. Disposal fees and other costs associated with radioactive and mixed waste remediation projects have to be entered by the user. ENVEST also allows the user to estimate escalation, contingency, project management, and contractor's indirect overhead and profit (OH\&P) as percentages of direct cost (Morse et al., 1995).

System Requirements

- Intel 386 based computer or higher

- $12 \mathrm{Mb}$ of hard disk space

- $640 \mathrm{~Kb}$ of memory

- DOS 3.2 or higher 


\section{$\mathrm{ReOpt}$}

\section{Version 3.1}

Developers: Battelle Pacific Northwest Laboratory

ReOpt is a decision support tool designed to assist engineers and planners in selecting site remediation technologies. ReOpt functions like an electronic encyclopedia by sorting and presenting information on available remediation technologies to the user. The system will help users focus quickly on technologies that will most likely be effective for a particular site. Information about these technologies is presented in a concise, easy-to-use format, helping users to identify key factors and constraints to consider in evaluating the use of a particular technology. ReOpt contains information on approximately 90 currently available remediation technologies. The information is divided into categories that describe the technology, explain where and how it is applied, and identify sources of additional information. ReOpt also contains auxiliary information about hazardous and radioactive contaminants and the federal regulations that govern their disposal. ReOpt includes a user-friendly graphical interface, and intuitively designed buttons, menus, and help lists. Information presented in ReOpt may be viewed on a computer screen or printed to a variety of printers (White and Bryant, 1993).

\section{System Requirements}

- Intel 80386 based computer or higher

- at least $4 \mathrm{Mb}$ of RAM

- VGA color monitor

- $3.5^{\prime \prime}$ high-density disk drive

$\underline{\mathrm{OR}}$

- Macintosh II class or higher

- $12 \mathrm{Mb}$ of hard disk space

- Standard 13" Macintosh color monitor
- DOS 3.3 or higher

- Windows 3.0 or higher

- $12 \mathrm{Mb}$ of hard disk space

- at least $5 \mathrm{Mb}$ of RAM

- $3.5^{\prime \prime}$ high-density disk drive

- System 6.0 or higher

\section{RESRAD}

Version 5.43

Developers: U.S. DOE (by Argonne National Laboratories)

RESRAD is a code that implements the analytical methodology recommended by the DOE for allowable concentrations of residual radioactive material in soil encompassed by the Formerly Utilized Sites Remedial Action Program (FUSRAP) and Surplus Facilities Management Program (SFMP) (DOE Order 5400.5). RESRAD is a multi- 
media model which incorporates a number of media-specific models. RESRAD uses a pathway analysis method in which the relation between radionuclide concentrations in soil and the dose to a member of a critical population group is expressed as a pathway sum, which is the sum of products of pathway factors. Pathway factors correspond to pathway segments, which connect various compartments in the environment. Radionuclides can be transported, or radiation can be transmitted between these compartments. Pathway analysis for deriving soil concentration guidelines for a specified dose limit is done in four stages including; 1) source analysis, 2) environmental transport analysis, 3) dose/response analysis, and 4) scenario analysis. Source analysis is done using a nondispersive equilibrium model of the leaching process. Nine potential exposure pathways are analyzed including direct exposure to external radiation from contaminated soil, internal radiation from contaminated dust, internal radiation from inhalation of radon, internal radiation from ingestion of plant foods grown on-site and irrigated with water drawn from an on-site well or pond, internal radiation from ingestion of meat from livestock fed with fodder grown on-site and water drawn from an on-site well or pond, internal radiation from milk from livestock fed with fodder grown on-site and water drawn from an on-site well or pond, internal radiation from direct ingestion of contaminated soil, internal radiation of aquatic foods from a nearby pond, and internal radiation from drinking water from an on-site well or pond (DOE, 1994). Environmental transport pathways include air (dust, radon, and other gases) and water (surface and groundwater). The groundwater pathway models only apply to situations for which hydrological strata can be reasonably approximated by a sequence of uniform, horizontal layers (EPA, 1993). RESRAD produces both tabular and graphical output. The tabular output provides detailed calculation results, including doses and risk from various pathways, concentrations in various media, maximum doses and minimum soil concentration guidelines. The graphical output displays calculation results for doses and concentrations, and sensitivity analyses.

\section{System Requirements}

- Intel 80i86 based computer

- math coprocessor (recommended)

- hard drive with $4 \mathrm{Mb}$ disk space

- at least $500 \mathrm{~Kb}$ of RAM

- color monitor (recommended)

- $\quad$ printer with 132-column output 


\section{RISK*ASSISTANT}

Version 2.0

Developers: Hampshire Research Institute

RISK*ASSISTANT for Windows is a code designed to rapidly estimate exposures and human health risks from chemicals in the environment at any site. This code quickly screens risks to identify the most serious threats from local contamination and sets priorities for action. Databases in the software provide U.S. EPA carcinogenic and noncarcinogenic toxicity data for 650 chemicals. The user can assess risks from air, surface water, groundwater, soil, sediments, and food. RISK*ASSISTANT provides 12 exposure pathways such as showering, eating locally produced food, and breathing indoor and outdoor air. The code combines the results of the user's exposure assessment with toxic hazard data to estimate risk (lifetime excess risk or hazard index) associated with the chemical under the specified conditions of exposure. A sensitivity analysis capability also displays the contribution that each selected exposure scenario makes to total exposure from a contaminated medium. On-screen sliding bars, dials, bar charts, and pie charts demonstrate the influence of assumptions made by the user on risk.

\section{System Requirements}

- Intel 80286 based computer or higher

- Windows 3.1 or higher

- hard drive with $8.5 \mathrm{Mb}$ disk space

- $4 \mathrm{Mb}$ of RAM

- laser or deskjet printer

\section{RISKPRO}

\section{Version 2.1}

Developers: General Sciences Corporation

RISKPRO is a code designed to provide comprehensive support for exposure assessment. RISKPRO contains extensive databases for chemical properties and climatic data from numerous U.S. sites. The code also includes the following models, each of which can be purchased separately: 1) ENPART (Environmental Partitioning Model), 2) EXAMS-II (Exposure Analysis Modeling System), 3) AT123D (Analytical Transient 1-2-3 Dimensional Model), 4) SESOIL (Seasonal Soil Compartment Model), 5) PTPLU (Single-source Gaussian dispersion algorithm), and 6) ISCLT (Industrial Source Complex Long Term Model). RISKPRO contains eight risk exposure routes including drinking water, soil ingestion, dermal contact with soil, inhalation of suspended soil/particulate matter, inhalation and dermal contact during 
showers, ingestion of fish, and ingestion of surface water while swimming. Other features include the ability to estimate the octanol/water partition coefficient, water solubility, boiling point, melting point, vapor pressure, Henry's Law Constant, bioconcentration factor, and adsorption coefficient. The program contains a data set for more than 1000 chemicals. Uncertainty analysis cannot be performed with this model (Block, 1995).

System Requirements

- Intel 80386 based computer or higher

- Windows 3.0 or higher

- math coprocessor (recommended)

- $4 \mathrm{Mb}$ of RAM

- hard drive with $24 \mathrm{Mb}$ disk space

- graphics display adapter

\section{SEDSS}

Version 1.0 (Beta testing began October 1995)

Developers: Sandia National Laboratories

The SEDSS is a tool for decision makers that will ultimately provide a basis for quantitative analyses in support of questions such as "What are the environmental and human health risks posed by a contaminated site?", "What is the best approach for remediating a site or establishing containment?", "How can it be determined and demonstrated to the regulator that remediation is complete or containment is effective?", "Is newly proposed waste disposal facility likely to comply with applicable regulatory criteria?", "Where should monitoring wells be placed to optimize contaminant detection?", and "Where should resources be applied to effectively address critical problems?". Potential applications for SEDSS include decision support for environmental characterization, decision support for environmental restoration, and risk assessment. When completed, SEDSS will utilize an iterative analysis approach that incorporates probabilistic risk analysis, cost/benefit analysis, and site sampling decision analysis techniques. Quantitative estimates of risk to human health and the environment are based on probabilistic analysis of site conditions that provides an explicit measure of uncertainty associated with the decision to be made. Results of the risk analysis can be used to direct additional site characterization and monitoring activities and to provide a consistent framework for comparing alternative system conceptualizations. New data will be used to repeatedly update the analysis and reduce uncertainty. To support the decision analysis, SEDSS will be designed to: 1) capture and store user input data and link to GIS site information, 2) guide the user through the process of developing a site conceptual 
model based on available information, 3) evaluate the conceptual model with physical process models, 4) allow explicit comparison of results with a performance objective, and 5) identify additional data needs. The automation of the SEDSS process is being developed using object-oriented software architecture that will allow for future expansion. The software architecture was designed utilizing case tools and the entire development process is being conducted using industry standard software quality assurance and configuration management methodologies. SEDSS will undergo multiple builds/releases during its lifecycle. The first release began Beta testing in October 1995. This release contains an automated decision framework for setting performance objectives, establishing existing information (i.e., information in a GIS), defining a conceptual model, running models in a Monte Carlo process, and displaying the uncertainty decision point that will allow a user to determine if a decision can be made or if it is necessary to continue through the rest of the decision framework steps. SEDSS development is partially funded by UMTRA. Development is also funded by the EPA's Superfund and Radiation Programs at EPA Headquarters, as well as the NRC's Waste Management Branch. SEDSS is a public domain computer program that is being designed to be a user-friendly, graphically-oriented, data and process model manager. The program will eventually contain complex process models (e.g., the USGS MODFLOW code) and stochastic methods (e.g., Latin Hypercube Sampling and Monte Carlo techniques) with seamless interfacing between modules.

System Requirements

- SUN workstation/Sun Server

\section{SitePlanner}

Version 2.0

Developers: Consolve, Inc. (Lexington, MA)

SitePlanner is an environmental data analysis and visualization tool. This code can integrate chemical, geological, hydrologic, planimetric, and topographic data from a variety of sources including DXF files from drafting systems, spreadsheets, and ASCII and $x$-Base text files. Data can be visualized on the computer screen in many different formats including maps, sections, and fence diagrams. Contaminant plumes, boring logs, scales, legends, contours, topographic, geologic, hydrologic, and chemical attribute data can be superimposed on these diagrams. In addition, scientific and engineering calculations can be performed on the data, such as geometric and 
arithmetic calculations to compute areas and volumes of contamination (including bounded cut and fills), and surface threshold regions. SitePlanner produces reportready Postscript output of all views in color and in black and white, customized tabular reports, and data files suitable for export to AutoCAD and other systems that use DXF files.

\section{System Requirements}

- Intel 80486 or Pentium based computer

- at least $24 \mathrm{Mb}$ of RAM

- $155 \mathrm{Mb}$ of swap space

- $\quad$ SCO ODT operating system

- three button serial mouse

- $600 \mathrm{Mb}$ of disk space

- ATI-graphics ultra SVGA card with 1024 x 768 noninterlaced $70 \mathrm{~Hz}$ monitor

$\underline{\mathrm{OR}}$

- $\quad$ SUN SPARC Station (IPC, IPX, SPARC2, SS10/30, SS10/41)

- Solaris 1.0 operating system

- at least $32 \mathrm{Mb}$ of RAM

- $1 / 4^{\prime \prime} 150 \mathrm{Mb}$ cartridge tape drive
- $16^{\prime \prime}$ or 19" color monitor

- $400 \mathrm{Mb}$ of disk space

- $75 \mathrm{Mb}$ of swap space

\section{SiteView}

Version 1.5

Developers: Consolve, Inc. (Lexington, MA)

SiteView is a $3 \mathrm{D}$ visualization and presentation tool for environmental data. Air quality, site remediation, fresh water and marine contamination, and other environmental data may be viewed. SiteView transforms base maps, geologic, and chemical data into 3D pictures of a site. SiteView accepts the following data; 1) 2D and 3D DXF maps from CAD or GIS systems, 2) spreadsheet and ASCII data, 3) sample results from boring wells and monitoring stations, and 4) data from groundwater models, risk analysis, contour and kriging packages. SiteView displays the following information in 3D images; 1) topographic and planimetric maps, 2) contamination plumes in air, soil, water bodies, and groundwater, 3) subsurface stratigraphy and groundwater flow information, and 4) relationship of contamination to topographic and operations features. All images are displayed in color and can be viewed from any perspective.

\section{System Requirements}

- Intel 80486 or Pentium based computer

- at least $8 \mathrm{Mb}$ of RAM
- Windows 3.1 or higher

- $20 \mathrm{Mb}$ of swapspace 


\section{SmartRISK/SmartTOX}

Version 1.0a

Developers: Pioneer Systems Development (Kirkland, WA)

SmartRISK is a code to perform risk assessments based on the EPA's December 1989 "Risk Assessment Guidance" or RAGS equations (EPA, 1989). It follows a process that combines data evaluation, exposure assessment, toxicity assessment, and risk characterization. In the data evaluation section of the code, users select the media and chemicals to be evaluated as well as the input chemical concentrations used to estimate reasonable maximum exposures and/or alternative concentration limits. Users also can import data from a spreadsheet program. The toxicity assessment, exposure assessment, and risk characterization sections follow the RAGS equations. Fate and transport models are not available in this code. The code includes a database of 100 chemicals. Chemicals can be added to the database through a subscription service that is updated quarterly. SmartTOX provides the latest toxicity data from the Integrated Risk Information System and Health Effects Assessment Tables (EPA, 1995). This feature increases the number of chemicals that can be included in a risk assessment to several hundred. SmartRISK can interface with a Monte Carlo program to provide cleanup level calculations and to allow users to create çustom input algorithms (Block, 1995).

\section{System Requirements}

- Intel 80386 based computer or higher

- $4 \mathrm{Mb}$ of RAM

- Windows 3.0 or higher

- math coprocessor (recommended)

- $10 \mathrm{Mb}$ of hard disk space

\section{Voxel Analyst}

Version 2.0

Developers: Intergraph Corporation

Voxel Analyst is a general-purpose 3D data visualization and analysis tool. Voxel Analyst accepts input from any grid-based modeling package (other than finiteelement models). A standard ASCII-data format is provided that allows multiple characteristics or attributes to be loaded into the same model. Data grids generated from contour maps can be loaded directly from ASCII grid files or from the following Windows NT products: MGE Terrain Analyst, MGE Modeler, and MGE Grid Analyst. Voxel Analyst provides five simple analytic-interpolation routines that allow a model to be generated from sparsely sampled data. Interpolation can be done 
globally using all sparse points within a data set or locally using points within a userspecified range. Several visualization displays are provided including chair diagrams, cross-sections, iso-surfaces, and iso-solids. All displays allow the user to define the percentage of transparency permitting visualization of multiple objects inside one another. The displays can be trimmed to any extent to improve comprehension and visualization, and then placed on different levels to allow independent or combined data displays. Three display modes are provided: sketch, wireframe, and shaded. The wireframe mode is used for rapid determination of display characteristics.

\section{System Requirements}

- Intel 80486 or higher based computer

- 256 color, $1024 \times 768$ pixel resolution
- Windows NT Version 3.51

- $16 \mathrm{Mb}$ of memory

\section{B. Recommended Decision Support Tools}

Table 5.1 presents a summary of the attributes of the decision support tools that have been reviewed in this report. Recommendations for decision support tools for use by the UMTRA groundwater restoration project will be made in four areas; 1) decision support tools to perform remediation project cost estimation, 2) decision support tools to optimize the placement of monitor wells and borehole sampling locations, 3) decision support tools to perform risk assessments to quantify the uncertainty in risk to the public and the environment, and 4) decision support tools to visualize and display data.

1. The attributes considered important for selection of a decision support tool to perform remediation project cost estimation include: 1) the capability to provide cost estimates on a wide-range of groundwater remediation alternatives, and 2) the capability quantify uncertainty in the cost estimate. Based on these criteria, the recommended cost estimation tool is CURE. This code is recommended for the following reasons:

a. CURE will have the capability to provide rapid cost analysis of remediation alternatives.

b. CURE will have the capability to provide quantitative uncertainty analysis of cost, including defensible contingency estimates.

c. CURE includes RACER (from Delta Research, Inc.), a cost estimation code that is widely used throughout the U.S. Department of Defense (DOD). 
2. The attributes considered important for selection of a decision support tool to perform optimization of monitor well and borehole placement include: 1) regulatory acceptance of the selected monitoring or sampling strategy, 2) the capability to minimize the total cost of monitor wells and boreholes based on a sound optimization strategy, and 3) the capability to account for uncertainty in contaminant migration. Based on these criteria and information presented in the introduction to this report, the recommended code for this area of decision support tools is BOSS. This code is recommended for the following reasons:

a. BOSS utilizes transport models in a probabilistic framework to account for uncertainty in contaminant movement.

b. BOSS utilizes optimization theory to minimize the number and cost of monitor wells and boreholes for sampling locations.

3. The attributes which are considered important for selection of a decision support tool to perform risk assessments to quantify the uncertainty in risk to the public and the environment include: 1) the capability to quantify the risk of the contaminants of concern at UMTRA sites including radionuclides, 2) the capability to perform a sensitivity analysis, and 3) the capability to perform risk assessments with multiple environmental exposure pathways. Based on these criteria and information presented in the introduction to this report, Précis is the recommended decision support tool for this area. This code is recommended for the following reasons:

a. Précis includes a modified version of the DOE's RESRAD code, to include radionuclides and hazardous constituents.

b. Précis includes a stochastic approach to estimating risk, using a Monte Carlo/Latin Hypercube Sampling method.

c. Précis includes a sensitivity analysis method to prioritize site characterization needs based on the relative importance of a parameter to the uncertainty in risk.

d. Précis includes nine environmental pathways for contaminant transport to a receptor.

e. Précis currently runs on both Macintosh and PC-based (Windows) platforms.

4. The attributes considered important for selection of a decision support tool to perform data visualization and display include: 1) the capability to import and export data in a variety of formats, 2) the capability to display data in a variety of 
formats, 3) the capability to rotate, translate, and zoom data displays, and 4) the capability to perform elementary calculations to determine the volume of contaminated soil and water. Based on these criteria, the recommended decision support tool for this area is SiteView. This code is recommended for the following reasons:

a. SiteView can accept data from a variety of sources and in many different formats including DXF maps, spreadsheets, and ASCII files.

b. SiteView can display data in a variety of formats and from any perspective.

c. SiteView can perform calculations to estimate the volume of contaminated media.

c. SiteView can run on a low-cost PC platform.

The major disadvantage to the use of these codes is the fact that the first three of the recommended codes, CURE, BOSS, and Précis are currently under development and, in their current state, do not completely to meet the needs of the UMTRA groundwater restoration project. Therefore, further development of these codes will be required. Until CURE development is completed, it is recommended that RACER be used as a remediation cost estimation tool. Likewise, it is recommended that PLUME and RESRAD be used until the development of the BOSS and Précis codes is completed.

Another risk assessment code that should be considered for use is SEDSS. Development of this code is being partially funded by the UMTRA project and will specifically assess risk to the public through the groundwater exposure pathway. However, since this code is not yet fully operational, other risk assessment codes (i.e. RESRAD and Précis) are recommended for immediate use by the UMTRA groundwater restoration project. 


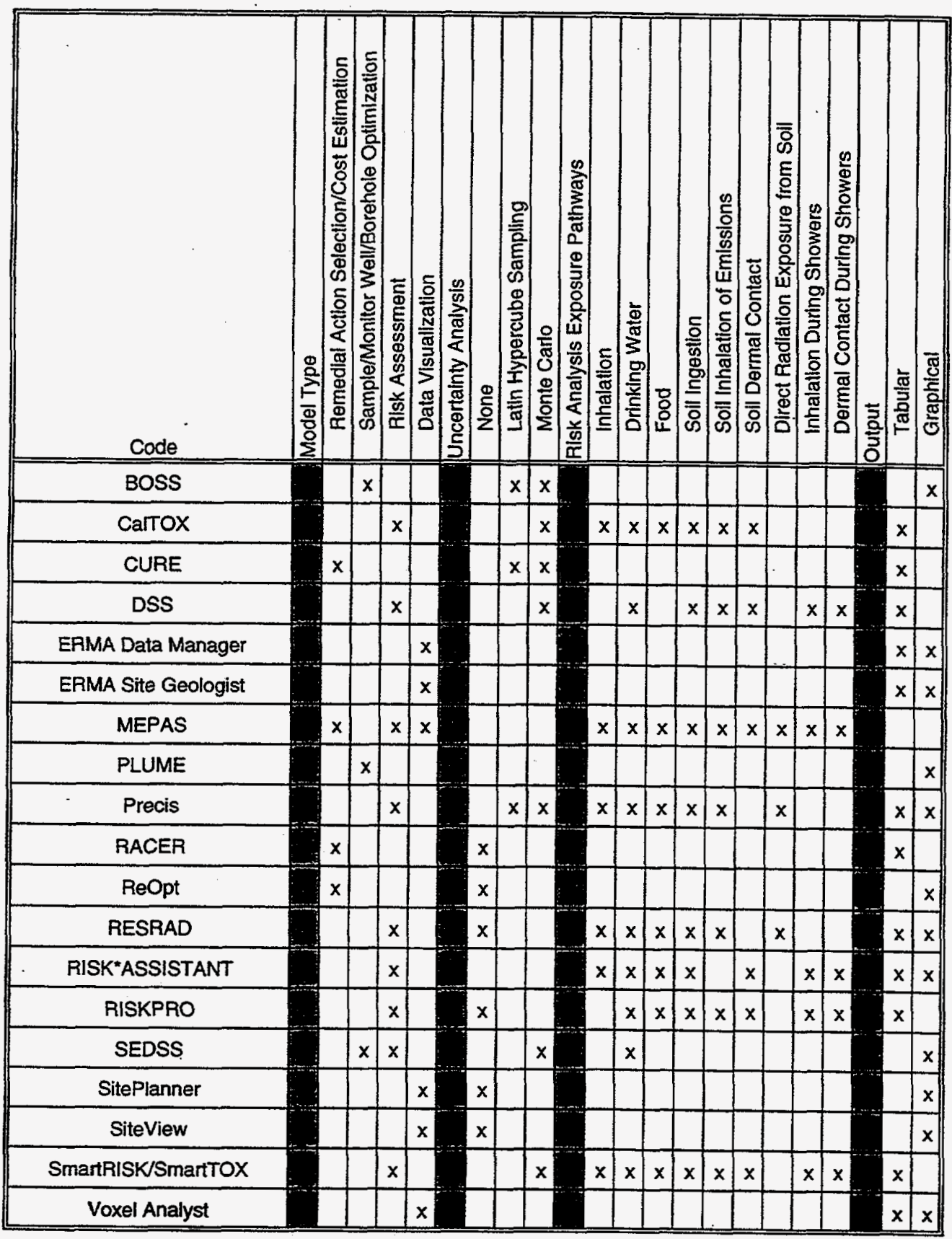

Table 5.1: Summary of Decision Support Tool Attributes 


\section{Section 6 \\ Conclusions}

\section{A. Summary of Code Survey}

The purpose of this report is to recommend computer codes for use by the UMTRA project for implementation of the observational approach to groundwater restoration. The observational approach uses a series of iterative steps which include characterization of a site, definition and refinement of a conceptual model of the site, and identification of uncertainties in the conceptual model. Successful implementation of the observational approach requires tools that optimize the use of available information, including numerical models and statistical techniques. This report contains recommendations for the following categories of computer codes: 1) groundwater flow and contaminant transport modeling codes, 2) hydrogeochemical modeling codes, 3) pump and treat optimization codes, and 4) decision support tools. For each category, a general survey of the various codes that are currently available was first presented. Then, a specific code (or codes) that best meets the needs of the UMTRA groundwater restoration effort was recommended. In addition, recommendations for future code development were made in categories where the current codes do not meet the needs of the UMTRA groundwater restoration project. General criteria for code selection included: 1) the availability of the code, 2) the cost of the code, 3 ) the platform required to run the code, and 4) the ability of the code to meet UMTRA needs as understood at this time. Preference was given to codes that are widely used, inexpensive, and run on low-cost platforms especially those that are already used by the UMTRA project. In cases where no currently available codes adequately meet the needs of the UMTRA groundwater restoration effort, future development is recommended for codes that can be enhanced within a short time frame (i.e., less than 2 years) to meet those needs.

Tables 6.1 and 6.2 contain a summary of the information presented in this report. The recommended code in each of the four categories is denoted by an asterisk. In addition, the table also contains the approximate cost and the source of each code. Addresses and telephone numbers for the sources of the codes are listed in the following section. 


\begin{tabular}{|c|c|c|c|}
\hline Model Type & Model Name & Source & Approximate Cost \\
\hline \multirow{18}{*}{$\begin{array}{l}\text { Groundwater Flow } \\
\text { and Contaminant } \\
\text { Transport Codes }\end{array}$} & FLONET/FLOTRANS & SSG & $\$ 1590$ \\
\hline & FTWORK & IGWMC & $\$ 250$ \\
\hline & GMS & SSG & $\$ 3500$ \\
\hline & HYDROGEOCHEM & SSG & $\$ 1500$ \\
\hline & INTERSAT/INTERTRANS & SSG & $\$ 600$ \\
\hline & LEHGC & SNL & $\mathrm{N} / \mathrm{C}$ \\
\hline & MODFLOW* & $\begin{array}{c}\text { IGWMC } \\
\text { SSG }\end{array}$ & $\begin{array}{l}\$ 350 \\
\$ 500 \\
\end{array}$ \\
\hline & MODPATH & IGWMC & $\$ 120$ \\
\hline & MT3D* & $\begin{array}{c}\text { IGWMC } \\
\text { SSG }\end{array}$ & $\begin{array}{l}\$ 500 \\
\$ 500 \\
\end{array}$ \\
\hline & PATH3D & IGWMC & $\$ 350$ \\
\hline & PHREEQM & Balkema & $\$ 45$ \\
\hline & PLASM & IGWMC & $\$ 120$ \\
\hline & RAND3D & IGWMC & $\$ 250$ \\
\hline & RANDOM WALK & IGWMC & $\$ 100$ \\
\hline & SUTRA & SSG & $\$ 500$ \\
\hline & SWIFT $/ 486$ & IGWMC & $\$ 800$ \\
\hline & TRACR3D & DOE & $\$ 250$ \\
\hline & VS2D/T & IGWMC & $\$ 250$ \\
\hline \multirow{6}{*}{$\begin{array}{c}\text { Hydrogeochemical } \\
\text { Codes }\end{array}$} & $\mathrm{EQ} 3 / 6^{*}$ & DOE & $\$ 250$ \\
\hline & MINTEQA2 & $\begin{array}{c}\text { IGWMC } \\
\text { SSG } \\
\end{array}$ & $\begin{array}{l}\$ 75 \\
\$ 250 \\
\end{array}$ \\
\hline & NETPATH & IGWMC & $\$ 120$ \\
\hline & PHREEQE & $\begin{array}{c}\text { IGWMC } \\
\text { SSG } \\
\end{array}$ & $\begin{array}{l}\$ 120 \\
\$ 350\end{array}$ \\
\hline & PHREEQC & USGS & $\mathrm{N} / \mathrm{C}$ \\
\hline & WATEQ4F & IGWMC & $\$ 120$ \\
\hline
\end{tabular}

(Note: N/C signifies no significant charge to the UMTRA Project; * Denotes Recommended Models)

Table 6.1: Summary of Groundwater Flow and Transport Models and Hydrogeochemical Codes 


\begin{tabular}{|c|c|c|c|}
\hline Model Type & Model Name & Source & Approximate Cost \\
\hline \multirow{6}{*}{$\begin{array}{c}\text { Pump and Treat } \\
\text { Optimization Codes }\end{array}$} & AQMAN3D & USGS & $\mathrm{N} / \mathrm{C}$ \\
\hline & FLOWPATH & IGWMC & $\$ 650$ \\
\hline & & SSG & $\$ 895$ \\
\hline & MODMAN & IGWMC & $\$ 550$ \\
\hline & OPTP/PTEST & IGWMC & $\$ 50$ \\
\hline & PLANET* & LLNL & $\mathrm{N} / \mathrm{C}$ \\
\hline \multirow{21}{*}{$\begin{array}{c}\text { Decision Support } \\
\text { Tools }\end{array}$} & BOSS* & SNL & $\mathrm{N} / \mathrm{C}$ \\
\hline & CalTOX & NTIS & $\$ 500$ \\
\hline & CURE* & SNL & $\mathrm{N} / \mathrm{C}$ \\
\hline & DSS & Geraghty \& Miller & $\$ 600$ \\
\hline & ERMA Data Manager & Intergraph & $\$ 4200$ \\
\hline & ERMA Site Geologist & Intergraph & $\$ 5900$ \\
\hline & MEPAS & DOE & $\$ 250$ \\
\hline & PLUME & ANL & $\mathrm{N} / \mathrm{C}$ \\
\hline & & Consolve & $\$ 700$ \\
\hline & Précis* & SNL & $\mathrm{N} / \mathrm{C}$ \\
\hline & RACER & Delta & $\$ 1000$ \\
\hline & $\mathrm{ReOpt}$ & DOE & $\$ 250$ \\
\hline & RESRAD & DOE & $\$ 250$ \\
\hline & RISK*ASSISTANT & Thistle Publishing & $\$ 400$ \\
\hline & RISKPRO & General Sciences & $\$ 5660$ \\
\hline & SEDSS & SNL & $\mathrm{N} / \mathrm{C}$ \\
\hline & SitePlanner & Consolve & $\$ 3495$ \\
\hline & SiteView* & Consolve & $\$ 495$ \\
\hline & & SSG & $\$ 495$ \\
\hline & SmartRISK/SmartTOX & Pioneer & $\$ 2250$ \\
\hline & Voxel Analyst & Intergraph & $\$ 5000$ \\
\hline
\end{tabular}

(Note: N/C signifies no significant charge to the UMTRA Project; * Denotes Recommended Models)

Table 6.2: Summary of Pump and Treat Optimization Codes and

\section{Decision Support Tools}




\section{B. Code Sources}

The following addresses and telephone numbers can be used to obtain software listed in Tables 6.1 and 6.2 .

ANL

Robert Johnson

Argonne National Laboratory

9700 S. Cass Ave.

Argonne, IL 60439

(708)252-7004

\section{Balkema}

A.A. Balkema Publishers

P.O. Box 1675

3000 BR Rotterdam, Netherlands

Telefax: 31104135947

\section{Consolve}

Consolve, Inc.

70 Westview Street

Lexington, MA 02173

Phone: (800)428-5547 or (617)674-2199

$\underline{\text { Delta }}$

Delta Research, Inc.

1501 Merchants Way

Niceville, FL 32578

Phone: (800)554-1145

\section{DOE}

Energy Science and Technology Software Center

P.O. Box 1020

Oak Ridge, TN 37831-1020

Phone: (615)576-2606

Fax: (615)576-2865

Internet: ESTSC@ADONIS.OSTI.GOV 
General Sciences

General Sciences Corporation

6100 Chevy Chase Drive

Laurel, MD 20707

Phone: (301)953-2700

Fax: (301)953-1213

Geraghty \& Miller

Geraghty \& Miller, Inc.

10700 Parkridge Blvd.

Suite 600

Reston, VA 22091

Phone: (703)768-1200

Fax: (703)758-1201

IGWMC

International Ground Water Modeling Center

Colorado School of Mines

Golden, CO 80401-1887

Phone: (303)273-3103

Fax: (303)384-2037

Internet: igwmc@mines.colorado.edu

Intergraph

Intergraph Corporation

Huntsville, AL 35894-0001

Phone: (800)345-4856

Fax: (205)730-9441

LLNL

T.W. Canales

Environmental Restoration Division, L-528

Lawrence Livermore National Laboratory

P.O. Box 808

Livermore, CA 94551 
NTIS

National Technology Information Service

5285 Port Royal Rd.

Springfield, VA 22161

Phone: (703)487-4600

Pioneer

Pioneer Systems Development

12902 N.E. 91 st Lane

Kirkland, WA 98033

Phone: (206) 822-4461

Fax: (206) 822-4637

SNL

Sandia National Laboratories

P.O. Box 5800

Albuquerque, NM 87185

Contact: Bob Knowlton (505-844-8533) for BOSS, CURE, and Précis

Contact: Eric Webb (505-848-0760) for SEDSS

Contact: Malcolm Siegel (505-844-5426) for LEHGC

$\underline{\text { SSG }}$

Scientific Software Group

P.O. Box 23041

Washington, D.C. 20026-3041

Phone: (703)620-9214

Fax: (703)620-6793

Thistle Publishing

Thistle Publishing

P.O. Box 1327

Alexandria, VA 22313-1327

Phone: (703)684-5203

Fax: (703)684-7704 


\section{$\underline{\text { USGS }}$}

U.S. Geological Survey

NWIS Program Office

437 National Center

Reston, VA 22092

(703)648-5695

\section{Future Development Work}

In most cases, currently available codes can meet the needs of the UMTRA groundwater restoration project. However, currently available codes in the decision support tools category do not meet these needs. Therefore, future development work is necessary in order to modify or enhance the currently available codes. Specifically, development is needed for the following three decision support tools:

1. CURE, the decision support tool to perform remediation cost estimates including quantification of uncertainty in those costs.

2. BOSS, the decision support tool to optimize the placement of monitor wells and borehole sampling locations.

3. Précis, the decision support tool to perform risk assessments for radioactive and hazardous contaminants and to quantify the uncertainty of risk to the public and the environment.

Further development of these decision support tools or other tools which will be capable of performing these tasks, will be required in order to implement the observational approach to groundwater restoration at UMTRA sites. It is expected that modifications to these codes could be completed in less than two years. 
(this page left blank) 


\section{Section 7 \\ References}

Anderson, M.P., and Woessner, W.W., 1992; Applied Groundwater Modeling: Simulation of Flow and Advective Transport, Academic Press, Inc., San Diego, CA, ISBN 0-12059485-4.

ANL, 1994; "PLUME: Software for Supporting Adaptive Sampling Programs - Technical Data Sheet", Argonne National Laboratory, Environmental Sciences and Engineering Group, January, 1994.

Appel, C.A., and Reilly, T.E., 1994; "Summary of Selected Computer Programs Produced by the U.S. Geological Survey for Simulation of Ground-Water Flow and Quality", U.S. Geological Survey Circular 1104.

Appelo, C.A.J., and Willemsen, A., 1987; "Geochemical Calculations and Observations on Salt Water Intrusions, I. A Combined Geochemical/Mixing Cell Model", Journal of Hydrology, 94, pp. 313-330.

Baker, K.H., and Herson, D.S., 1994; Bioremediation, McGraw-Hill, Inc., New York, NY.

Block, R.M., 1995; "Software Packages Ease Risk Assessment Tasks", Environmental Solutions, March, 1995.

Canales, T.W., Tompson, A.F.B., Ziagos, J.P., and Nichols, E.M., 1992; "PLANET: An Interactive Computer System for the Rapid Generation and Evaluation of Ground Water Pump and Treat Scenarios", Lawrence Livermore National Laboratory, UCRL-JC-109674.

DOE, 1994; "Energy Science and Technology Software Center: Software Listing", United States Department of Energy, ESTSC--2/Rev.3, September, 1994.

DOE/UMTRA, 1993; "Technical Approach to Groundwater Restoration", Jacobs Engineering Group, Inc., DOE/AL/62350-20F. 
EPA, 1989; "Risk Assessment Guidance for Superfund (RAGS)", Vol. I, Human Health Evaluation Manual (Part A), OSWER Directive 9285.7-01A, Office of Emergency and Remedial Response, Washington, D.C.

EPA, 1993; "Computer Models Used to Support Cleanup Decision-Making at Hazardous and Radioactive Waste Sites", U.S. Environmental Protection Agency, EPA 402-R93-005.

EPA, 1994; "Identification and Compilation of Unsaturated/Vadose Zone Models", U.S. Environmental Protection Agency, EPA/600/R-94/028.

EPA, 1995; "Integrated Risk Information System (IRIS)", On-line database, Maintained by the U.S. Environmental Protection Agency, Washington D.C.

Gorelick, S.M., Freeze, R.A., Donohue, D.R., Keely, J.F., 1986; "Determining the Most Efficient and Cost-Effective Pumping Schemes for Treating Contaminated Aquifers", Chem-Nuclear Geotech, Inc., U.S. Department of Energy Contract No. DE-AC07$86 \mathrm{ID} 12584$.

Hsieh, P.A., and Freckleton, J.R., 1993; "Documentation of a Computer Program to Simulate Horizontal-Flow Barriers Using the U.S. Geological Survey Modular ThreeDimensional Finite-Difference Ground-Water Flow Model", U.S. Geological Survey Open-File Report 92-477.

Hoffman, F., 1993; "Ground-Water Remediation Using 'Smart Pump and Treat'", Ground Water, Vol. 31, No. 1.

IGWMC, 1995; "IGWMC Ground-Water Software Catalog: Summer 1995", International Ground Water Modeling Center, Colorado School of Mines, Golden, CO, 804011887.

INTERA Environmental Consultants, 1983; "Geochemical Models Suitable for Performance Assessment of Nuclear Waste Storage: Comparison of PHREEQE and EQ3/EQ6", Battelle Memorial Institute, Office of Nuclear Waste Isolation, ONWI473, Columbus, $\mathrm{OH}$. 
Kincaid, C.T., and Morrey, J.R., 1984; "Geochemical Models for Solute Migration, Vol. 2, Preliminary Evaluation of Selected Computer Codes", Electric Power Research Institute, EA-3417, Palo Alto, CA.

Leake, S.A, Leahy, P., and Navoy, A.S., 1994; "Documentation of a Computer Program to Simulate Transient Leakage from Confining Units Using the Modular FiniteDifference Ground-Water Flow Model", U.S. Geological Survey Open-File Report 94-59.

Leake, S.A., and Prudic, D.E., 1991; "Documentation of a Computer Program to Simulate Aquifer-System Compaction Using the Modular Finite-Difference Ground-Water Flow Model", Techniques of Water-Resources Investigations of the U.S. Geological Survey, Book 6, Chapter A2.

McDonald, M.G., and Harbaugh, A.W., 1984; "A Modular Three-Dimensional Finite Difference Ground Water Flow Model: MODFLOW", U.S. Geological Survey Open File Report, 83-875.

Morse, M.A., Valdez, J.M., and Cox, W.B., 1995, "A Conceptual Cost Estimate for Remediation Activities at a Multisite Federal Facility", Remediation, Summer, 1995.

Nordstrom, D.K., Plummer, L.N., Wigley, T.M.L., Wolery, T.J., Ball, J.W., Jenne, E.A., Bassett, R.L., Crerar, D.A., Florence, T.M., Fritz, B., Hoffman, M., Holdren, G.R. Jr., Lafon, G.M., Mattigod, S.V., McDuff, R.E., Morel, F., Reddy, M.M., Sposito, G., and Thrailkill, J., 1979; "A Comparison of Computerized Chemical Models for Equilibrium Calculations in Aqueous Systems", Chemical Modeling in Aqueous Systems (ed. E.A. Jenne), ACS Symposium Series 93, pp. 857-892.

Parkhurst, D.L., Thorstenson, D.C., and Plummer, L.N., 1980; "PHREEQE - A Computer Program for Geochemical Calculations", U.S. Geological Survey Water-Resources Investigations Report 80-96.

Plummer, L.N., Prestemon, E.C., and Parkhurst, D.L., 1991; "An Interactive Code (NETPATH) for Modeling Net Geochemical Reactions along a Flow Path", U.S. Geological Survey Water-Resources Investigations Report 91-4078. 
Prickett, T.A., and Lonnquist, C.G., 1971; "Selected Digital Computer Techniques for Groundwater Resource Evaluation", Illinois State Water Survey, Bulletin 55.

Prickett, T.A., Naymik, T.S., and Lonnquist, C.G., 1981; "A 'Random Walk' Solute Transport Model for Selected Groundwater Quality Evaluations", Illinois State Water Survey, Bulletin 65.

Scientific Software Group, 1995; "1995 Software Bulletin", Scientific Software Group, Inc., Washington D.C.

Swain, E.D., and Wexler, E.J., 1993; "A Coupled Surface-Water and Ground-Water Flow Model for Simulation of Stream-Aquifer Interaction", U.S. Geological Survey OpenFile Report 92-138.

Travis, B.J., 1984; "TRACR3D; A Model of Flow and Transport in Porous/Fractured Media", Los Alamos National Laboratory, Report LA-9667-MS, Los Alamos, NM.

Truesdell, A.H., and Jones, B.F., 1974; "WATEQ, A Computer Program for Calculating Chemical Equilibria of Natural Waters", Jour. Research U.S. Geological Survey, v. 2 , No. 2, pp. 233-248.

Walton, W.C., 1992; Groundwater Modeling Utilities, Lewis Publishers, Chelsea, MI, ISBN 0-87371-679-5.

White, M.K., and Bryant, J.L., 1993; "ReOpt ${ }^{\mathrm{TM}}$ : Version 2.1", Pacific Northwest Laboratories, PNL-7840, Rev. 1, UC-602, 630.

Wolery, T.J., 1979; "Calculation of Chemical Equilibrium between Aqueous Solution and Minerals: The EQ3/6 Software Package", Lawrence Livermore National Laboratory Report, UCRL-52658.

Yeh, G.T., and Tripathi, V.S., 1990; "HYDROGEOCHEM: A Coupled Model of Hydrological Transport and Geochemical Equilibrium of Multi-Component Systems", Oak Ridge National Laboratory, ORNL-6371. 
Yeh, G.T., 1993; "Users' Manual for LEHGC: A Lagrangian-Eulerian Finite-Element Model of Hydrogeochemical Transport Through Saturated-Unsaturated Media Version 1.0", Sandia National Laboratories Contractor Report, SAND93-7081.

Zheng, C., 1988; "PATH3D 3.0: A Ground-water Path and Travel-time Simulator", S.S. Papadopulos \& Associates.

Zheng, C., 1990; "A Modular Three-Dimensional Transport Model for Simulation of Advection, Dispersion and Chemical Reactions of Contaminants in Ground Water Systems", U.S. Environmental Protection Agency, Robert S. Kerr Environmental Research Laboratory, Ada, OK. 
(this page left blank) 


\section{Section 8 Acknowledgments}

The authors would like to thank Dr. David Peterson (Intera, Inc.) and Bob Galloway

(Sandia National Laboratories) for their extensive reviews of this report prior to publication. 
(this page left blank) 


\section{Distribution:}

\section{External:}

Mushtaq A. Khan (5)

IT Corporation

5301 Central Avenue NE, Suite 700

Albuquerque, NM 87108-1513

Don Metzler (5)

U.S. DOE/Grand Junction

P.O. Box 2567

Grand Junction, CO 81502-2567

Sandia National Laboratories/NM:

MS0726 J.K. Rice, 6600

MS0715 R.E. Luna, 6652

MS0719 J. E. Nelson, 6621

MS0720 C.D. Massey, 6626

MS0720 R.G. Knowlton, 6626

MS0736 N.R. Ortiz, 6400

MS0734 L.D. Bustard, 6472

MS0734 M.D. Tucker, 6472 (15)

MS1147 R.B. Galloway, 7582

MS0899 Technical Library, 4414 (5)

MS0619 Print Media, 12615

MS0100 Document Processing, 7613-2

For DOE/OSTI (2)

Sandia National Laboratories/CA:

MS9018 Central Technical Files, 8523-2 